\title{
دور التشريع والقضاء الدوليين في مكافحة جريمة الإبادة الجماعية
}

$$
\begin{aligned}
& \text { نايف أحمد ضاحي الشمري و عمر عباس خضير العبيدي } \\
& \text { قسم القانون، كلية الحقوق، جامعة تكريت-العراق } \\
& \text { (تاريخ القبول بالنشر:10 كانون الثاني، 2021) }
\end{aligned}
$$

الحخلاصة

يعد هذا البحث من الدراسات التي تظهر خطورة الجرائم الدولية المرتكبة ضد الإنسانية، والجههود الدولية المبذولة لضمان أعمال حقوق الانسان وإنصاف الشعوب ووقف الممارسات اللاإنسانية ضد الممدنيي أثناء الحروب.

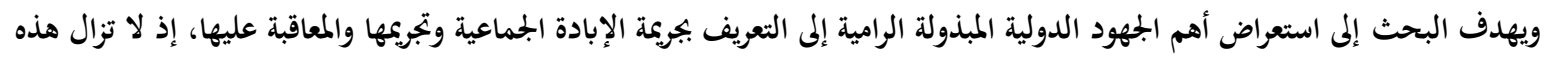

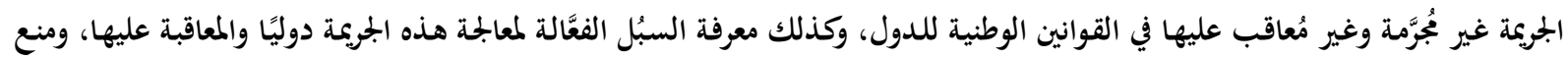
وقوعها من قِبل الدول في المستقبل. وتعد الجرائم الدولية الماسة بالجنس البشري من أشد الجرائم خطورة ضد البشر، إذ إنها تنطوي على مساس بحياة شخص أو مجموعة من

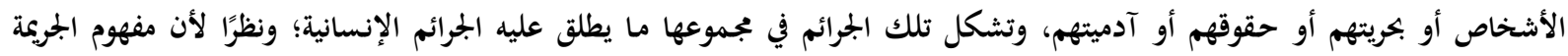

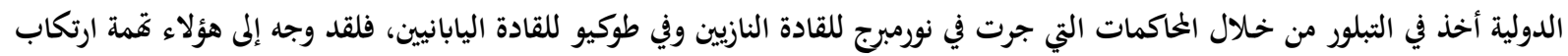

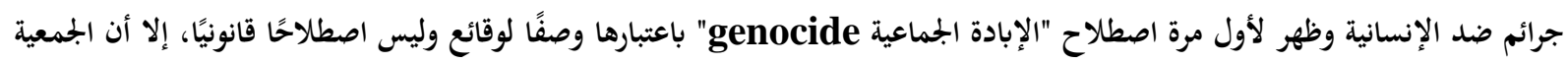
العامة للأمم المتحدة قد تبنت في 11 ديسمبر 1946 توصية وصفت فيها الإبادة الجمماعية بأنما جريمة من جرائم القانون الدولي.

$$
\text { الكلمات المفتاحية : الجنس البشري، ضد الانسانية ، القتل الجماعي، القتل. }
$$

الحياة أو الصحة، أو صورة بيولوجية كما في إعاقة النسل أو حرمان جماعة من النسل للتكاثر عن طريق التعقيم والإسقاط،

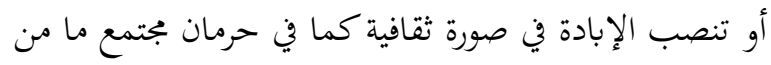
لغته أو ثقافته (الإبادة الثقافية). ثانياً: إشكالية البحث تطور مفهوم جرائم الإبادة الجماعية في القانون والقضاء

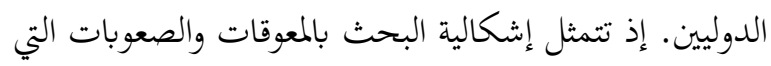
تواجه منظمة الأمم المتحدة والمحكمة الجنائية الدولية في أداء

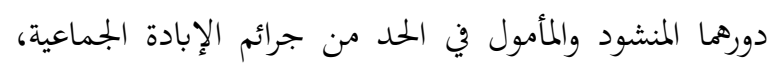
بوصفها المحكمة الوحيدة للقضاء الجنائي الدولي الدائم، التي هي صاحبة الولاية الجنائية العالمية...

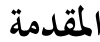

ان للتشريع والقضاء الدوليين أثرًا واضحًا وكبيرًا في

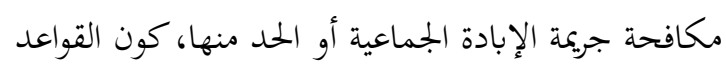
القانونية الدولية وما يصدر عن مختلف المحاكم والهيئات القضائية الدولية ذات أثر ملزم ، من حيث الأصل.

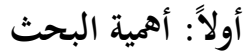
ان أهمية البحث تتمثل باعتبار ان جريمة الإبادة الجماعية

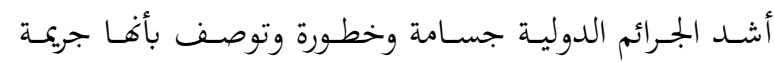
الجرائم، وذلك لما تشكله من تمديد للإنسان في حياته وصحته

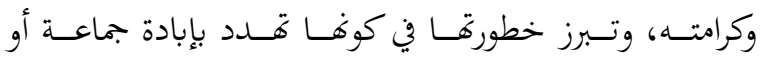
جماعات كاملة لأسباب دينية أو عرقية أو عنصرية أو قبلية ...

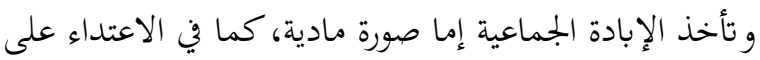
Omarabbas93.aa@gmail.com 
يتضح من ذلك أن الجريمة الدولية تمس مصلحة دولية معتبرة

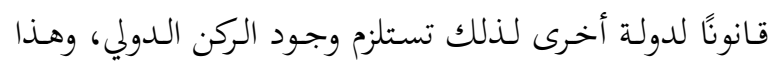
الركن هـو الـذي يميزز الجريمـة الدوليـة عـن الجريمـة الداخليـة. وباعتبـار أن جريمـة الإبادة الجماعيـة تنتمي إلى طائفـة الجـرائم

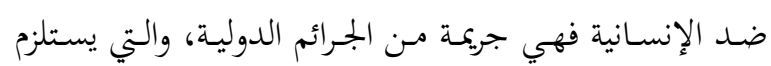
لقيامها توفر أركان الجريمة العادية فضلاً عن الركن الدولي.

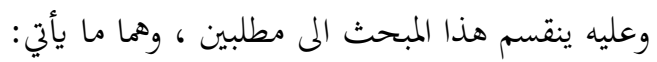

المطلب الأول: التعريف بجريمة الإبادة الجماعية المطلب الثاني: أركان جريمة الإبادة الجماعية وتطبيقاتحا

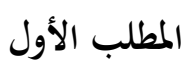
التعريف بجريمة الإبادة الجماعية أن أول ظهور لمصطلح الإبادة الجماعية في أدبيات القانون وفي الفكر الإنساني كان عام 1944 من خلال كتابات العالم الألماني "Raphael Lemkin" الذي اقترح وصف الأفعال المـدمرة للجـماعات القوميـة أو الاجتـماعية أو الدينيـة بــأفا "جريمة من جرائم قانون الشعوب Deicto Jurisgentim "

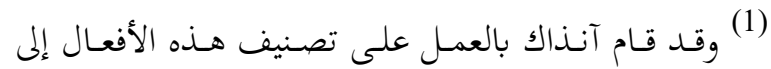

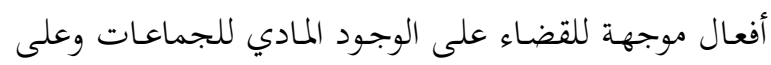

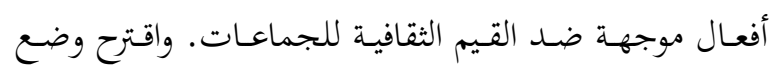
اتفاقية دولية للقضاء على هذه الجريمة والمعاقبة عليها (2).

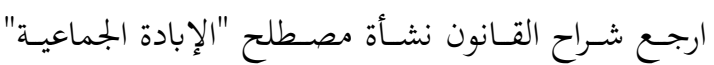
(Genocide)

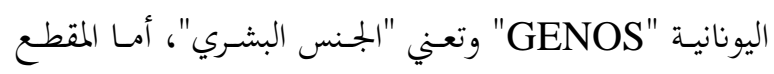

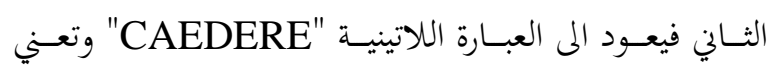

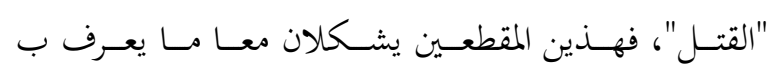

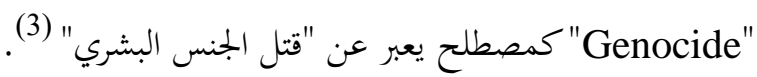

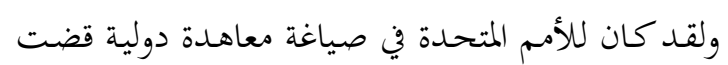
بمنع جريمة الإبادة الجماعية والعقاب عليها أقرتا الجمعية العامة

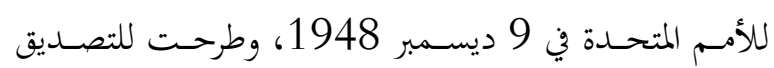
عليها من جانب الدول، ودخلت حيز التنفيذ في 12 يناير 1951 بعدما أكتمل لها نصاب التصديقات اللازم لنفاذها.

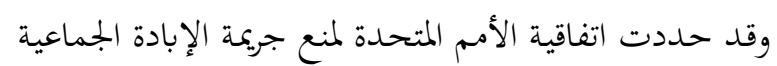

ثالثاً: منهجية البحث بالنظر للخصوصية التي تتميز بها جرائم الإبادة الجماعية

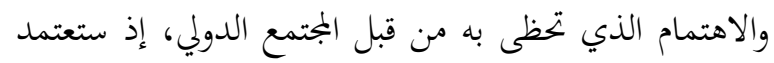

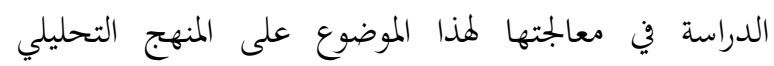

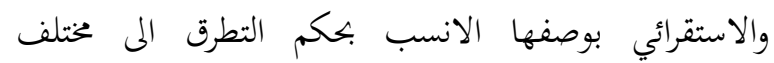

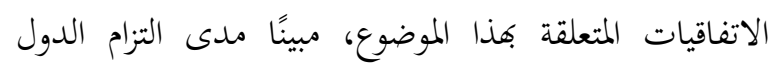
بالعمل وفق القواعد الدولية لمكافحة جرائم الإبادة. رابعاً: هيكلية البحث وفي العواعث البحل ومن اجل بيان دور التشريع والقضاء الدوليين في مكافحة جريمة الإبادة الجماعية تم تقسيم البحث الى مبحثين: المبحث الأول: ماهية الإبادة الجماعية وتطبيقاتجا

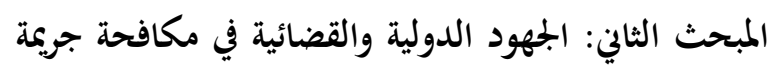
الإبادة الجماعية

\section{المبحث الأول}

\section{ماهية الإبادة الجماعية}

لقد شهد المجتمع الدولي منذ الحرب العالمية الثانية حروبًا استخدمت فيها شتى ما جادت به من وسائل الشر والإيذاء

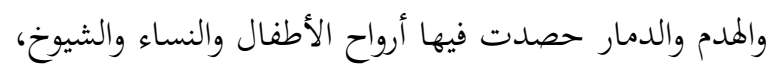

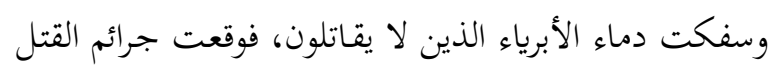

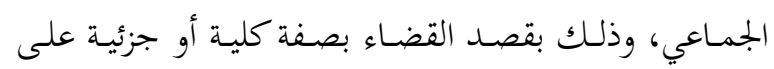

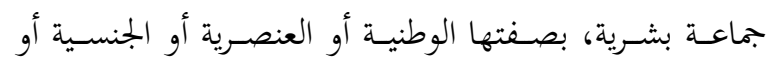

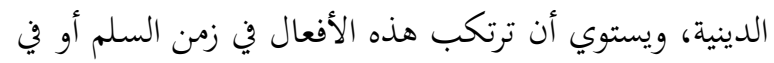

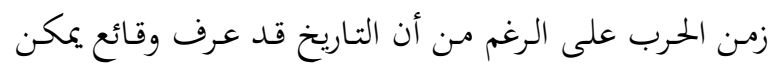

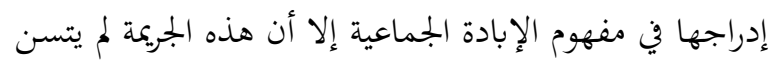

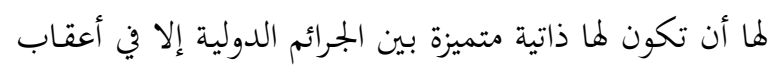

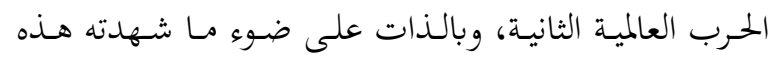
الحرب من ارتكاب فظائع راح ضحيتها ملايين البشر.

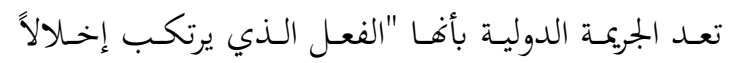

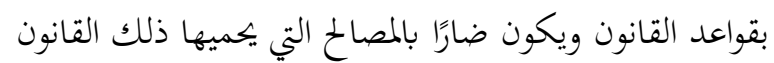

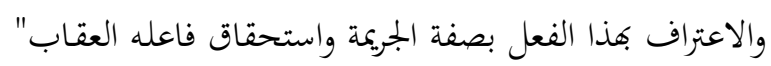


بأفراد الجماعة، أو باتخاذ إجراءات تمنع تناسلها، أو النقل

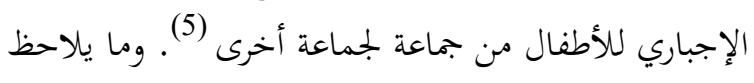

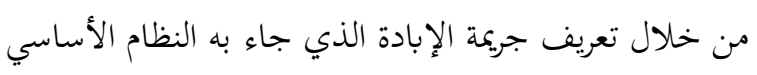

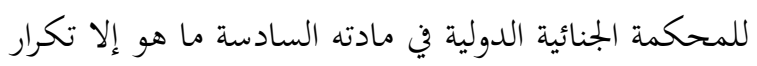

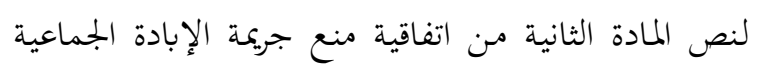

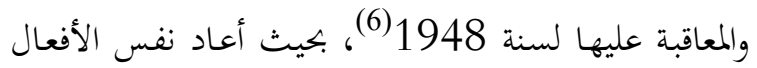

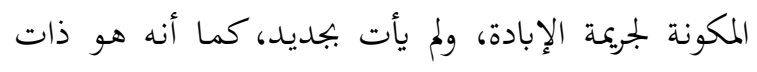

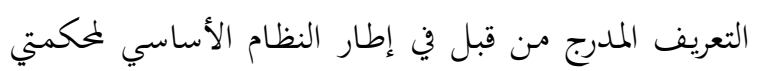
يوغسلافيا سابقا ورواند (7). وقد أورد قانون المحكمة الجنائية العراقية المختصة بالجرائم ضد الإنسانية تعريفًا للإبادة الجماعية يماثل التعريف الوارد في

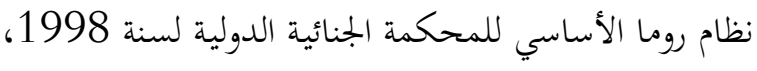

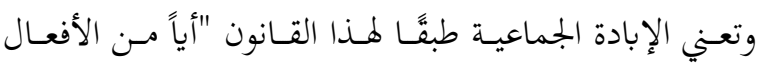

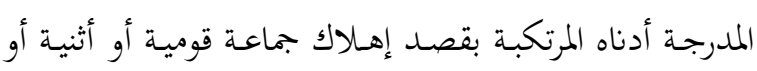
عرقية أو دينية، بصفتها هذه، إهلاكاً كلياً أو جزئياً". أ- قتل أفراد من الجماعة.

ب- إلحاق ضرر جسدي أو عقلي جسيم بأفراد الجماعة.

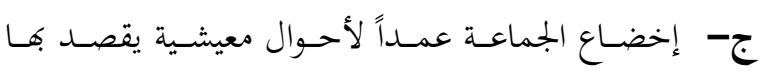
إهلاكها الفعلي كلياً أو جزئياً. د- فرض تدابير تستهدف منع الإنجاب داخل الجماعة. هـ - نقل أطفال من الجماعة عنوة إلى جماعة أخرى (8).

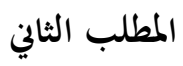

\section{أركان جريمة الإبادة الجماعية وتطبيقاتما}

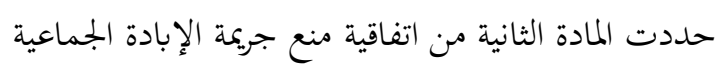
ومعاقبة مرتكبيها صور الركن المادي لجريمة الإبادة، التي أقرتها

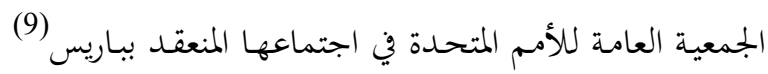
إذ عرفت مفهوم الإبادة أها: "كل عمل يرمي إلى إفناء شامل لماهل أو جزئي لإحسدى المجموعـات القومية أو العرقية أو الدينيـة". وكمثال على ذلك، قتل أبناء تلك الجماعة القومية أو الطائفية

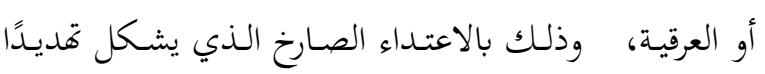

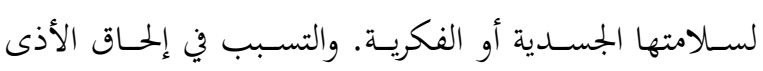

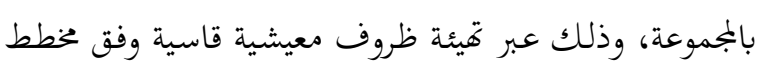

والمعاقبة عليها لعام 1948 النطاق الزمني لوقوع جريمة الإبادة

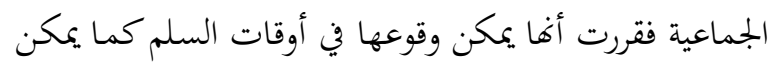

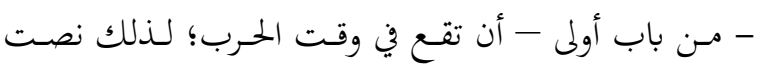

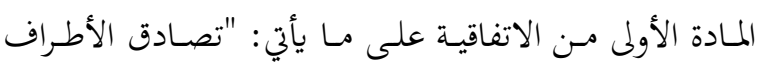
المتعاقدة على أن الإبادة الجماعية سواء ارتكبت في أيام السلم

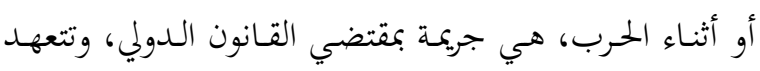

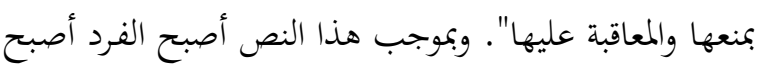

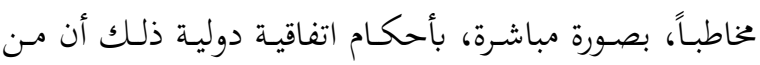
يرتكب مـن الأفراد جريمـة تـدخل في نطـاق الإبادة الجماعيـة تجري معاقبته بناء على نص دولي مستمد من اتفاقية دولية.

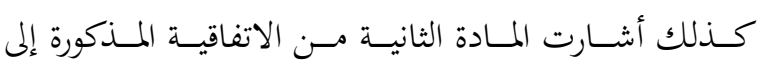
الجماعات التي تشملها قواعدها بالحماية، فلقد جاءت المادة

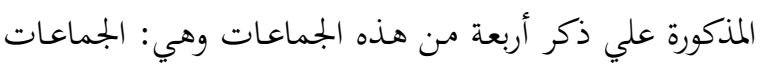

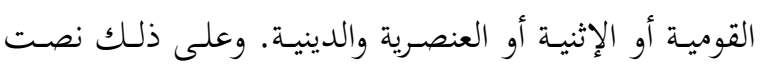

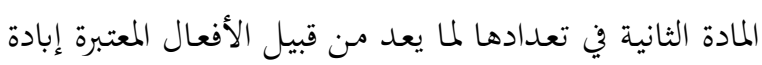

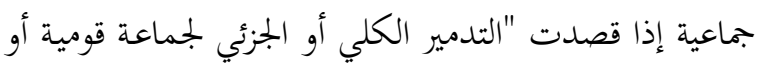
إثنية أو عنصرية أو دينية بصفتها هذه ...".

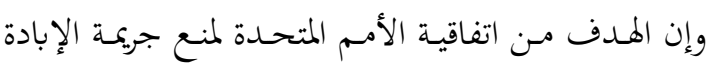
الجماعية والمعاقبة عليها هو حماية البشرية من أفعال تؤدي كليًا

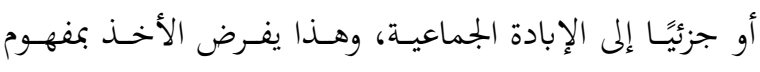

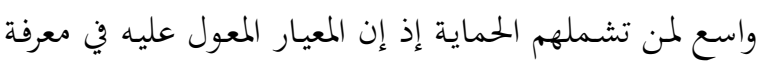

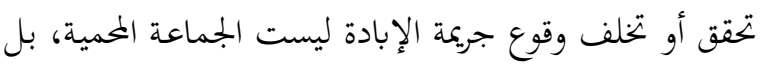

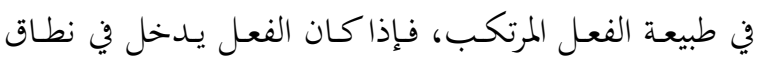

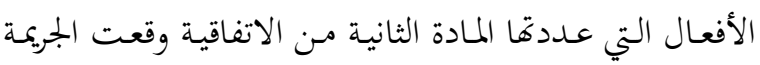

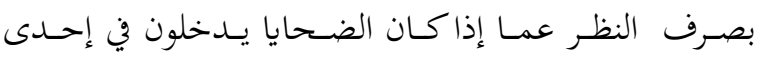

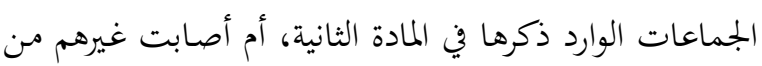
البشر (4) وقد عرف النظام الأساسي للمحكمة الجنائية الدولية

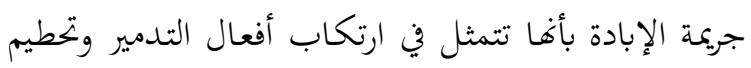

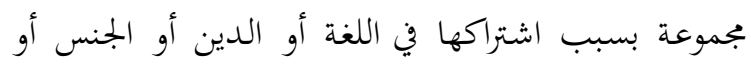

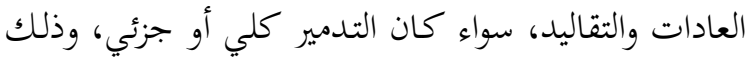
عن طريق القتل، أو بأحداث أذى جسماءني أو عقلي جسيم النيم 
جزئًا. (د) فرض تدابير تستهدف الحؤول دون إنجاب

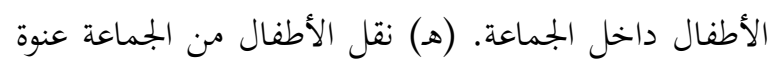

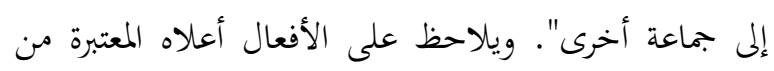

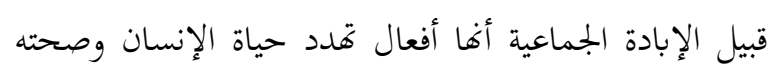

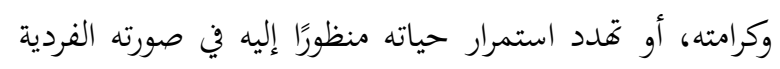

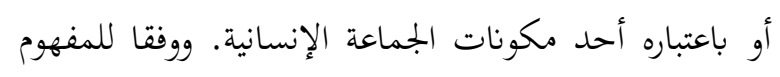

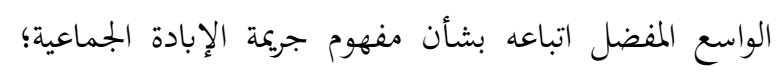

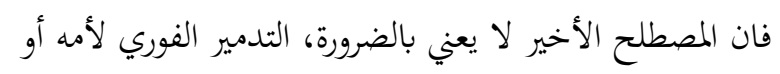

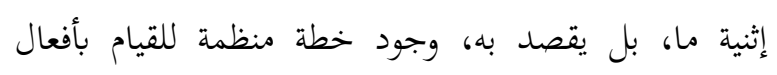
مختلفة تحدف إلى القضاء على الأسس والركائز الحيوية التي

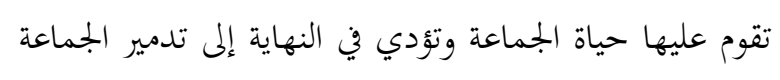
ذاتا؛ ولذلك فإنه يعد من قبيل الإبادة الجماعية: إفناء

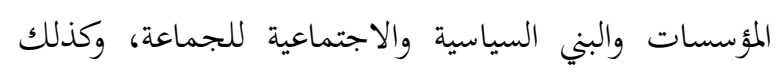

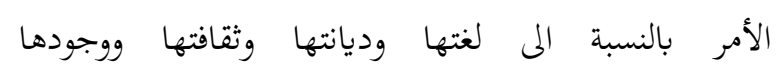

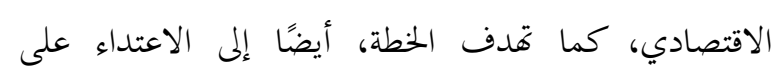

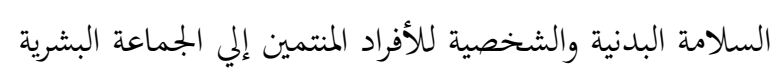

$$
\text { محل الإبادة (13). }
$$

وبشأن الأفعال التي يشملها العقاب على جريمة الإبادة،

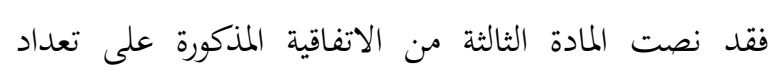

$$
\text { للأفعال التي ينالها العقاب عند وقوعها، وهي: }
$$

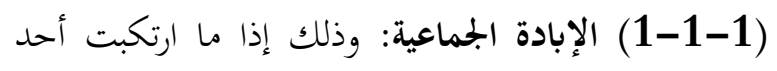

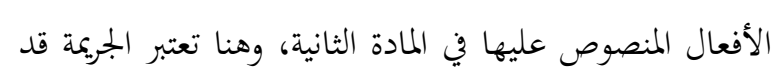

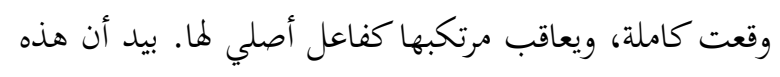

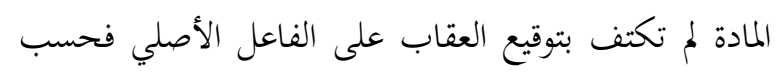

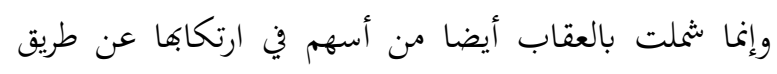
الاشتراك بإحدى الصور التي عرفتها القوانين الوطنية للاشتراك اكت إكناك

(1-1-1-2) التآمر على ارتكاب الإبادة الجماعية: وهذه

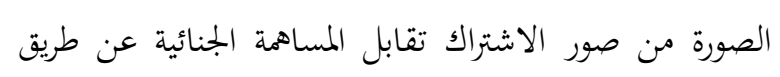
"الاتفاق" في القوانين الجنائية الوطنية، ويراعي أن هذه الأفعال

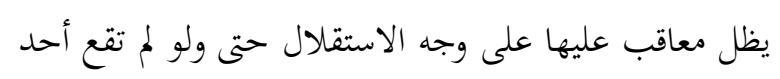

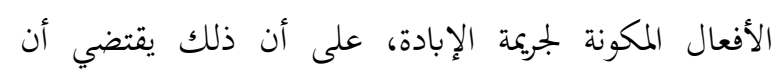

Nady-law2000@yahoo.com;
يقصد من وراءه تعجيل هلاك المجموعة وإفنائها كليًا أو جزئيًا.

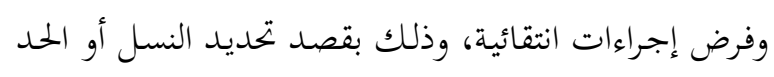

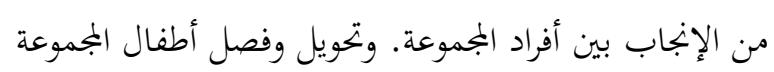

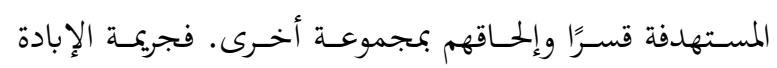
الجماعية تم تعريفها من قبل فقهاء القانون الدولي، على أها:

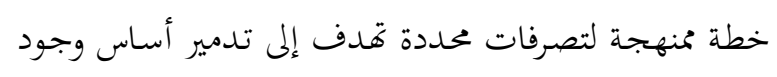

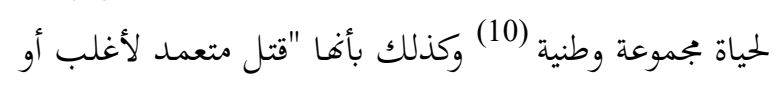

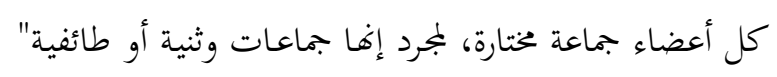

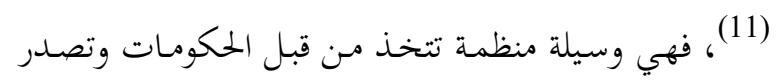

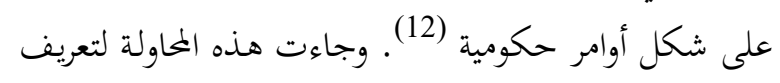

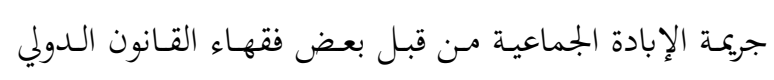

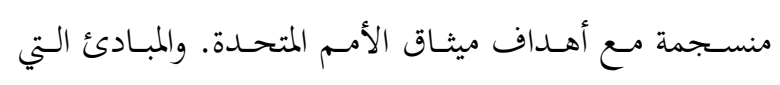

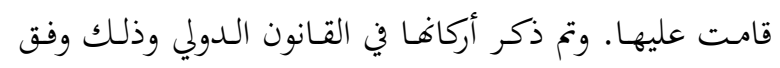

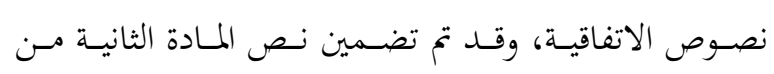

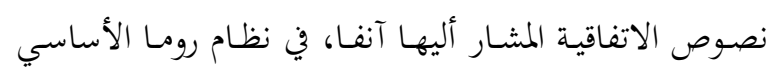
كجريمة معاقب عليها بموجب الميثاق وكذلك الحال في المادة السادسـة مس نصوص القـانون الأساسي للمحكميـة الدوليـة

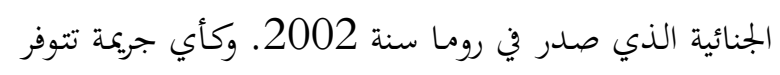
فيها إبادة الجنس البشري على أركان عامة، هي الركن المادي

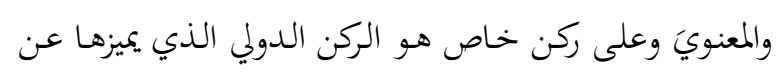

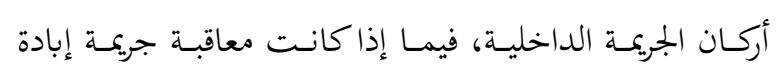

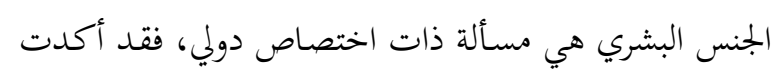

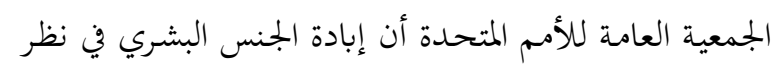

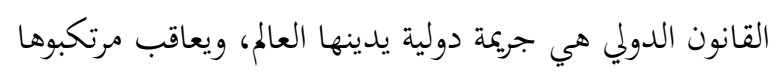

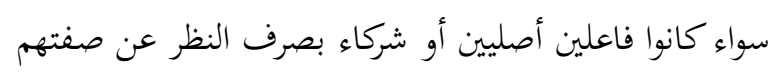
حكامًا كانوا أو أفرادًا عاديين. أولاً الركن المادي: عددت الماداد افرادادين الثانية من الاتفاقية المذكورة

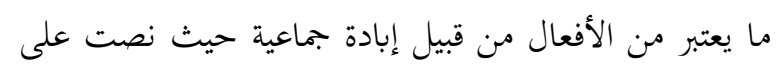

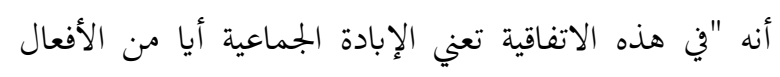

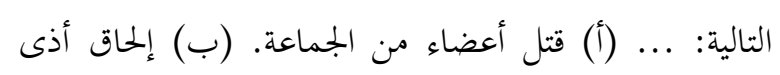

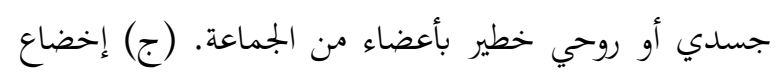

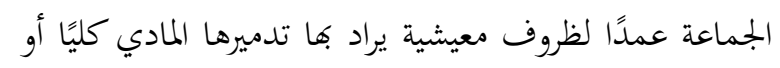


ثانياً: الركن المعنوي: يتمثل الركن المعنوي في جريمة الإبادة

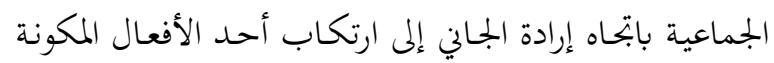

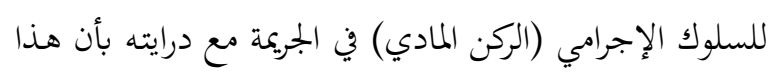

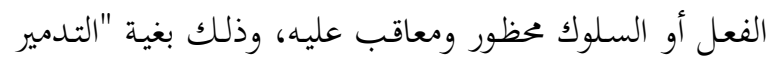

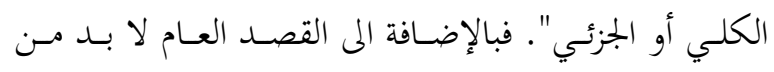

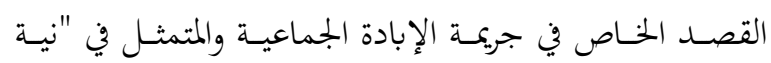

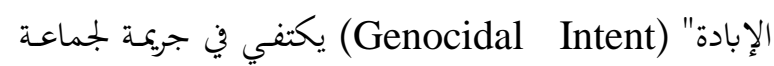
قومية أو إثنية أو عرقية أو دينية (19).ويجب لقيام جريمة الإبادة

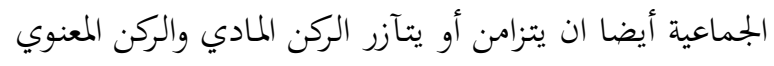

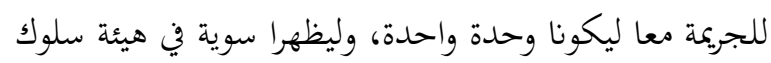

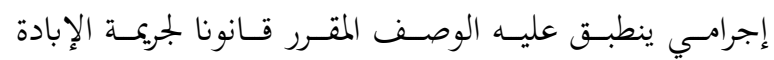

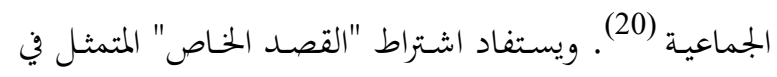
نية الإبادة من التعريف الوارد لهذه الجريمة في نص المادة الثانية

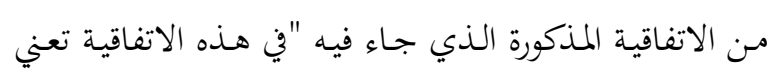

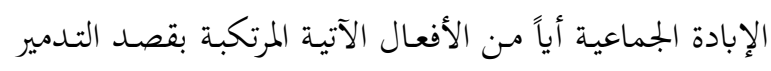

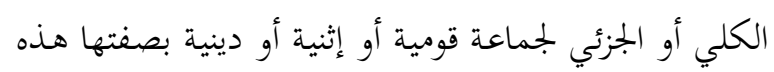
."...

وليس هناك تلازم بين توافر نية إحداث النتيجة المنصوص

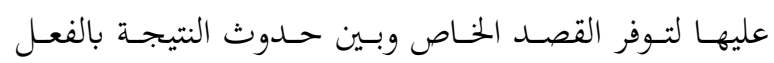

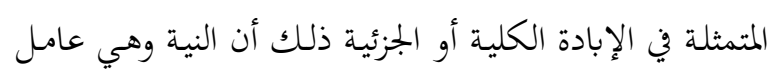

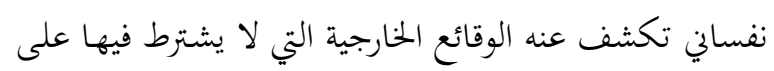

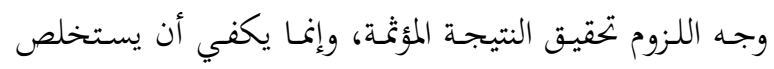

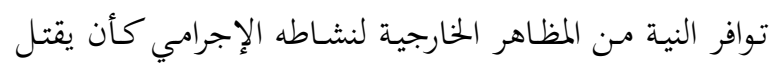

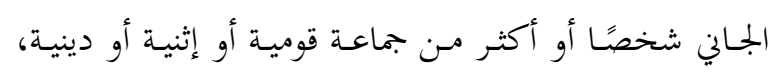

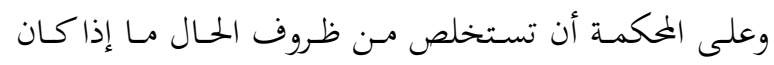
ذلك تنفيذًا لنية استقرت لديه في إحداث عمل من أنس أعمال

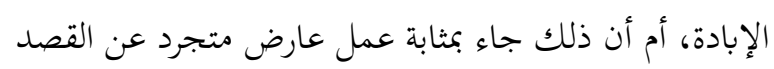
الخاص المتمثل في نية الإبادة (21). وبشأن تحديد مفهوم نية "التدمير الكلي أو الجزئي" التي لتئي تمثل القصد الخاص المميز لهذه الجريمة كما نصت عليه اتفاقية

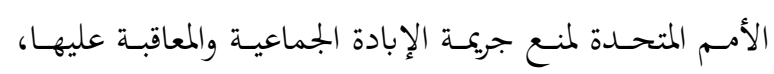

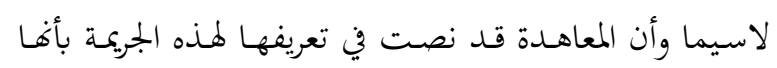

يتجاوز النشاط المعاقب عليه بجرد النفكير في ارتكاب أحد

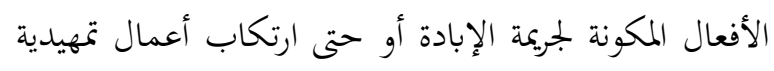

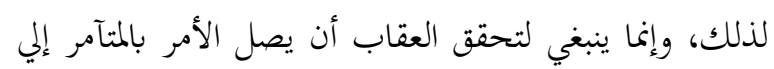

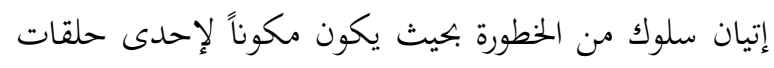
ارتكاب الجريمة، ويبقي تقدير هذا كله للمحكمة التي تتولي النظر في الدعاوى المتعلقة بهذه الجريمة (15). (1-1-1) التحريض المباشر والعلني على ارتكاب الإبادة

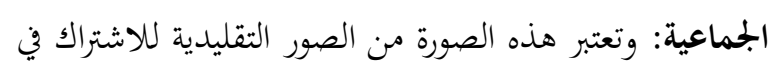

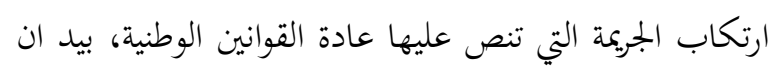

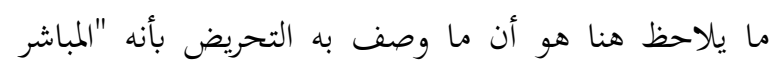

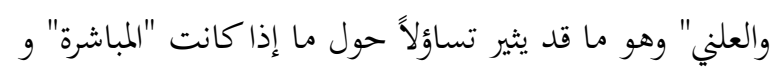

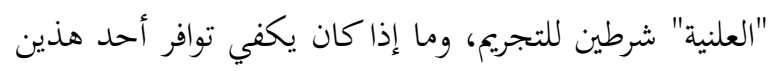

$$
\text { الوصفين أم يشترط تلازمهما حتى تقوم الجريمة؟ }
$$

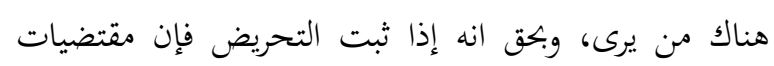

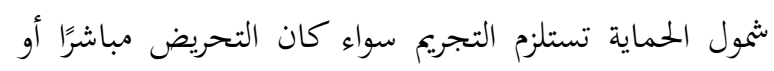

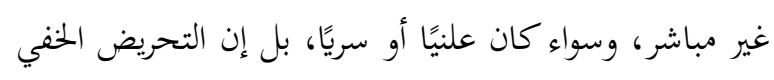
قد يكون أكثر خطرًا من التحريض العلني؛ لأنه قد يشتبه عليه بالتآمر والأخير، كما سبق ذكره، صورة من صور الأعمال التي يشملها العقاب (16).

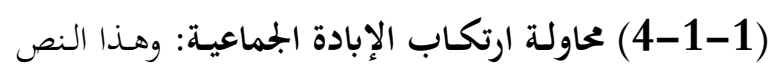

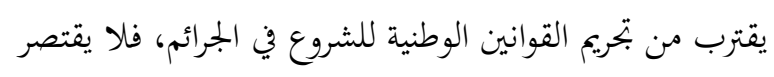

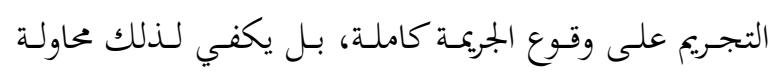

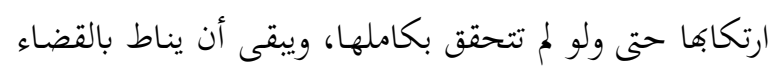

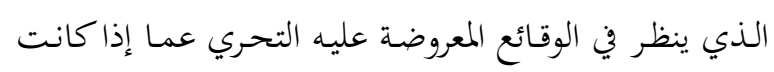

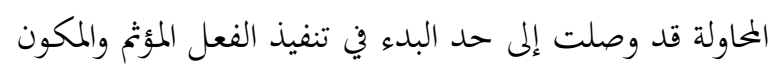

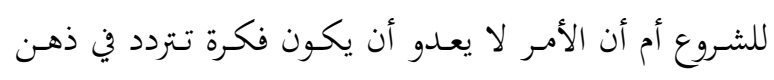

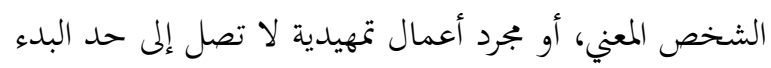
في التنفيذ الذي يصدق عليه وصف المحاولة (17). (c)

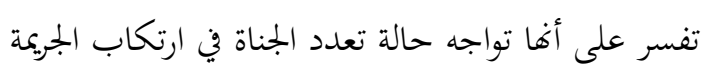
لينالمم العقاب وبنفس القدر (18). 
الدوليـة في الجريمـة أن تتضـمن عنصـرًا دوليًا، وتتحقـق هـذهـ الصفة الدولية في الحالات الآتية: (1)

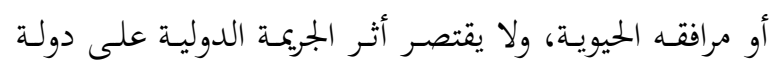

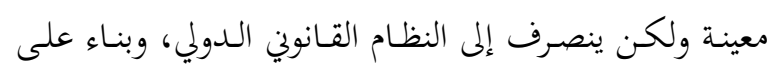
ذلك فإن الجريمة الدولية هي عدوان على المصالح التي يحميها القانون الجنائي الدولي. (1-1-2) ويشترط في الغالب لتحقق الركن الدولي أن تقع

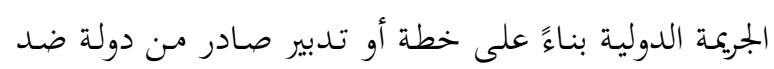

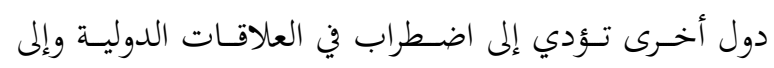
اختلال بالنظام العام الدولي. (1-1-3) يشترط لتحقـق صـفة الدوليـة أن يكـون الفعـل

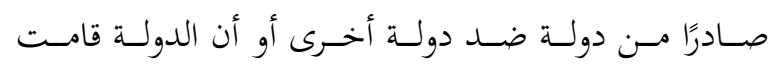

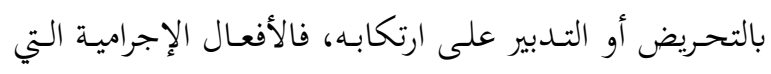

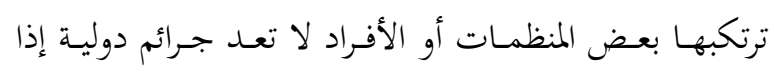

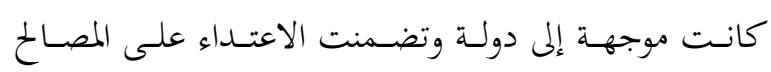

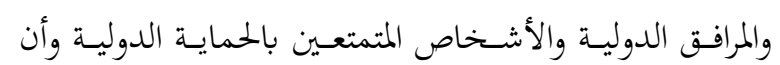
كانت هذه الأفعال ها صلة بأي دولة. (1-1-4) وتكتسب الجريمة صفة الدولية في حالة الاضطهاد الذي يقع لأسباب سياسية أو عنصرية أو دينية كحالة الجرائم

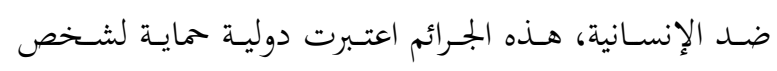

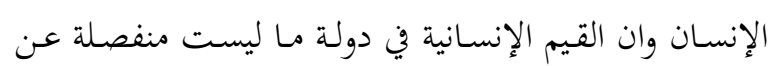
المجتمع الدولي الذي يهمه مصير أبنائه في كل أنحاء العالم.

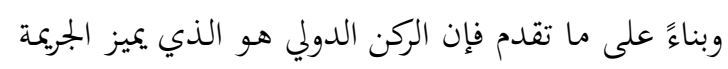

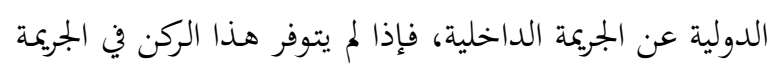

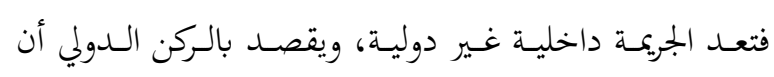
ترتكب الجريمـة مـن جانب دولة ضـد دولـة أخرى، كجـرائم

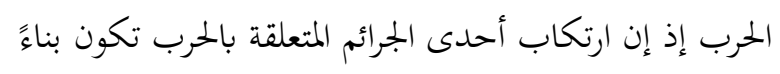

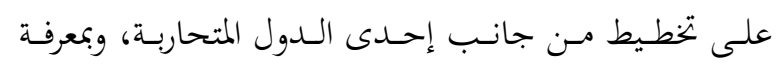

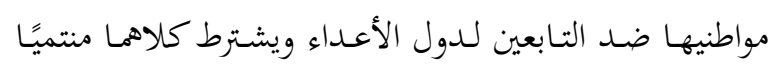

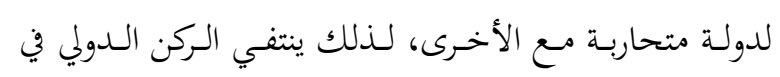

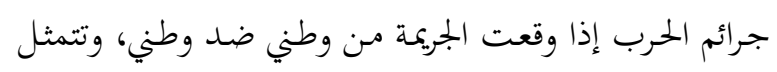

تعني "التدمير الكلي أو الجزئي". وبغض النظر عما قيل من

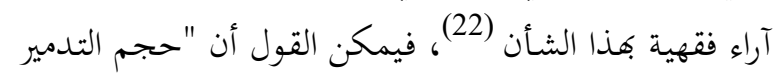

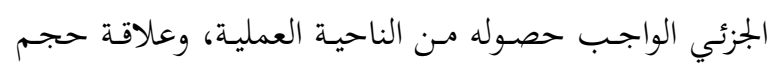

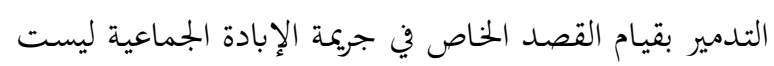

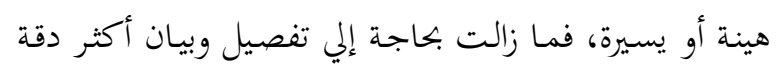

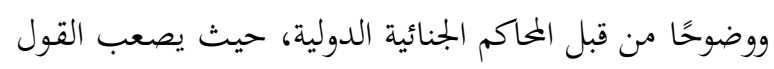

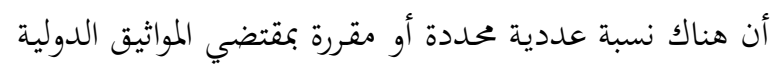
في هذا الخصوص" (23) ـوقد تم تفسير عبارة "التدمير الكلي أو الجزئي" من خلال الاجتهادات القضائية بأها تعني القضاء

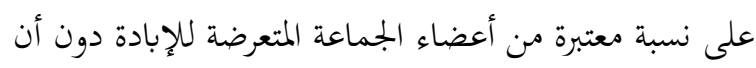
يكون للمساحة الجغرافية التي وقعت فيها الإبادة اعتبار (24).

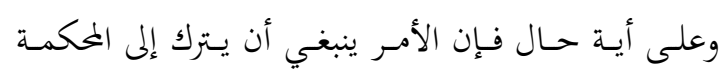

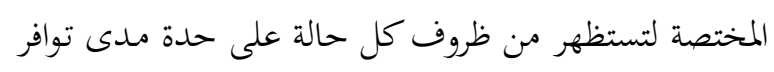
القصد الخاص، فقد يقترف الجاني لمرة واحدة الفعل المؤثم ولم

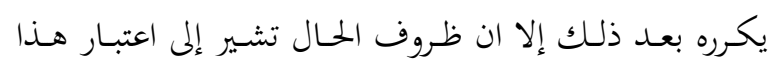

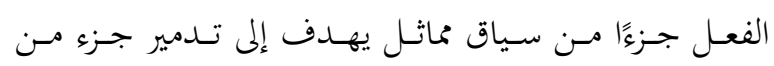

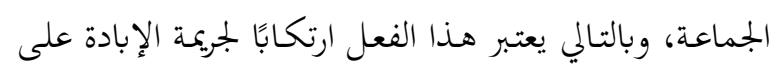

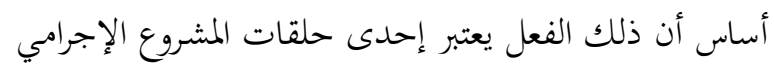

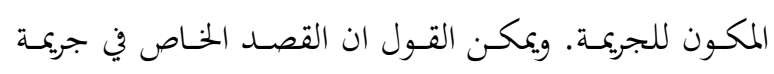

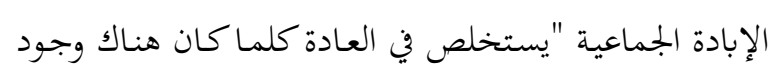

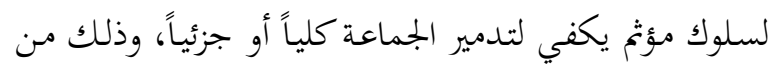
خلال التحقق من وجود العلم بالسياق القائم على إحـداث

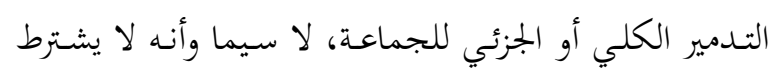

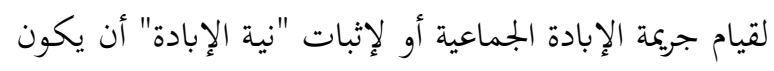

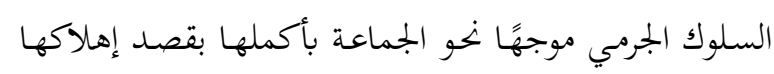
بصورة كلية. ثالثا: الركن الدولي: تعرف الجريمة الدولية بأها "كل سلوك

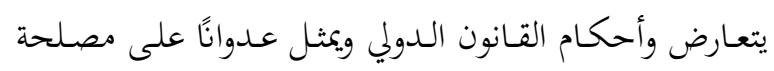

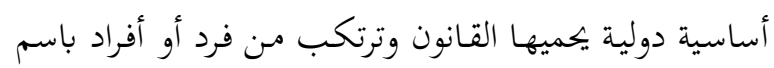

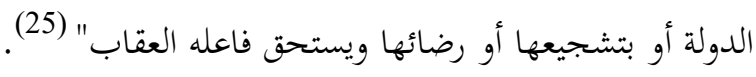

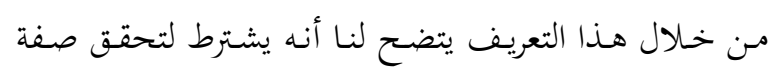


الذي فرضته على العراق. الذي تسبب في وفاة أعداد كبيرة

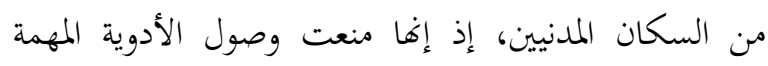

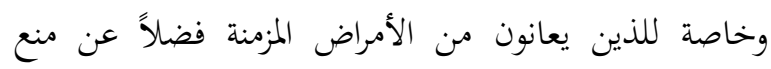
وصول الغذاء، وقد حصل ذلك في إطار هجوم واسع النطاق ومنهجي، شنته الولايات المتحدة والدول المتحالفة معها، وطال أعدادًا كبيرة من السكان المدنيين (29). ومن التطبيقات الأخرى على هذه الجريمة هي ما قام به الهيد النظام السابق من قصف لمدينة حلبجة بالأسلحة الكيمياوية، إذ تسبب في إبادة الآلاف من السكان المدنيين (30).

\section{المبحث الثاني}

\section{الجهود الدولية والقضائية في مكافحة جريمة الإبادة الجمماعية}

تشــتمل اتفاقيـة منــع جريكـة الإبادة الجماعيـة ومعاقبــة

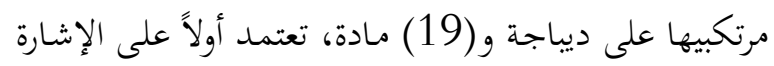

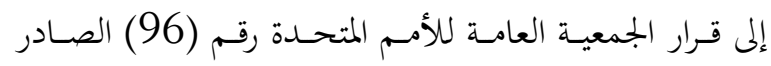
بتـاريخ 1946/12/16، أن الإبادة هي مـن أخطر الجـرائم

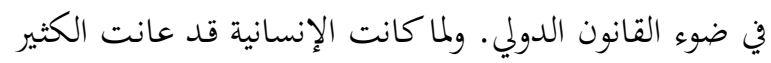

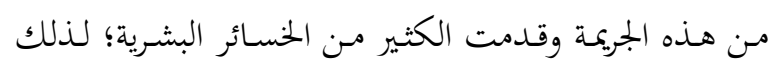
يعتقد المجتمع الدولي بضرورة التعاون من أجل خلاص الجمن البشرية

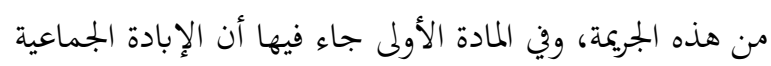

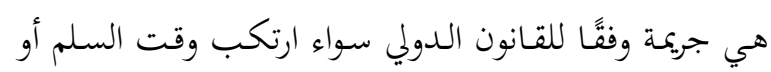
وقت الحرب.

وافقت الجمعية العامة للأمم المتحدة على اتفاقية مكافحة

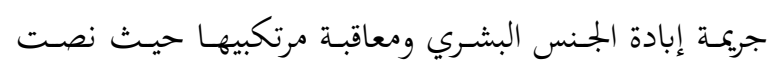

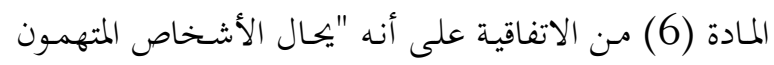

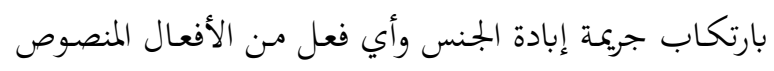

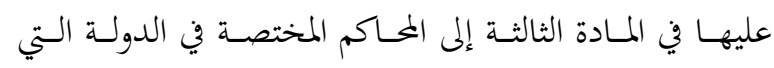

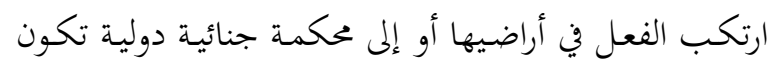

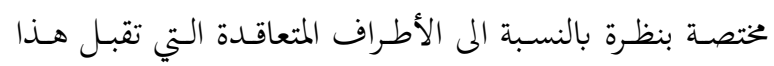
الاختصـاص". مـن الواضـح أن الـنص المـذكور آنفًا يمسنح
جــائم الحــرب في القتـل وســوء معاملــة الأســـى وتــدمير المدن.... الخ (26).

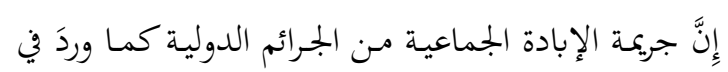

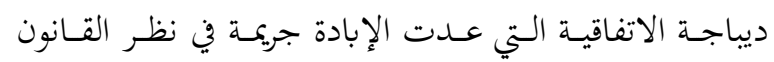

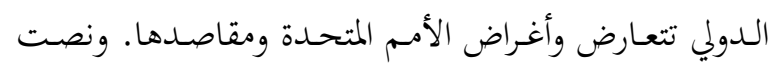

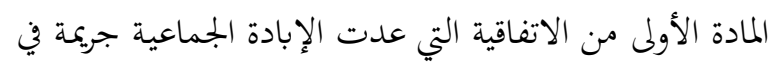

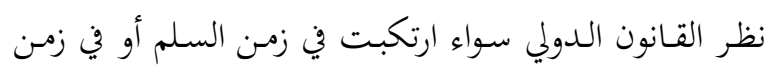

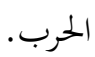

مـن هنــا نجـــ أن الـركن الـدولي يجـب أن يتـوفر في هـــه

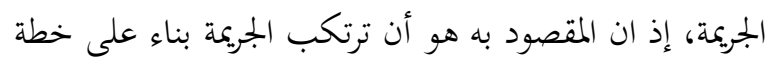

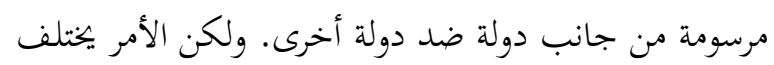
في هــهه الجريمـة، إذ أشـارت المـادة (4) مــن اتفاقيـة الإبادة

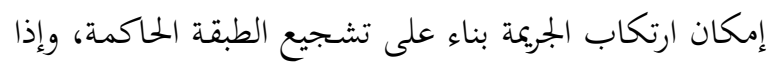
كانـت قـد تصـورت إمكـان ارتكاهـا عـن طريـق بقيـة أفراد

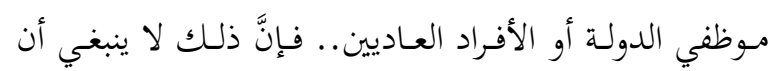

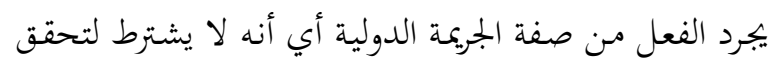

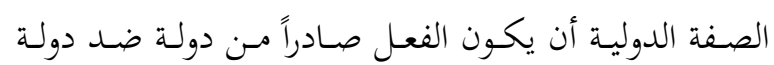
أخرى (27).

بل يكفي لقيام الركن الدولي في هذه الجريمة هو أن تكون

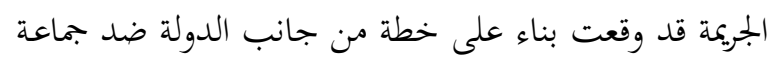
بشرية ذات عقيدة معينة ولو كانت تتمتع بذات جنسية الدولة

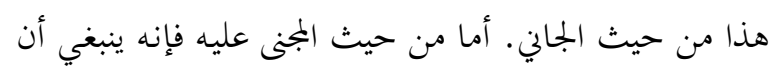

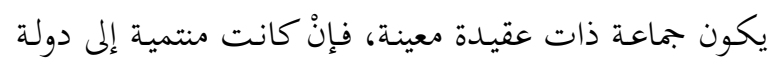

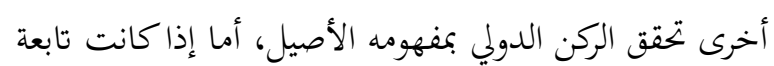

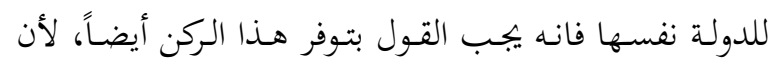

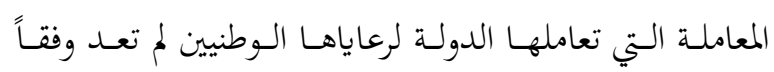

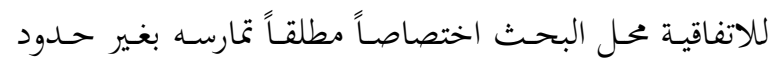

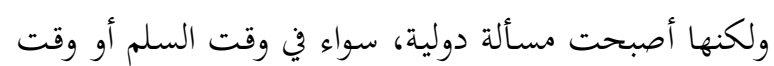

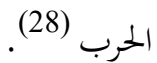
تطبيقات جريمة الإبادة الجماعية: إن من التطبيقات هذه

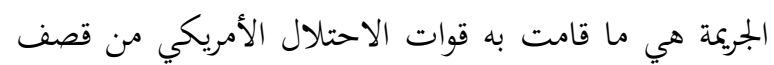

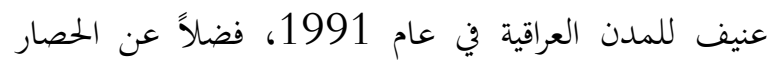


بسلطات فرع من الفروع، وعلى ذلك نصت المادة العاشرة من

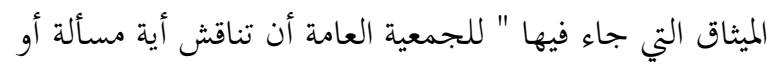

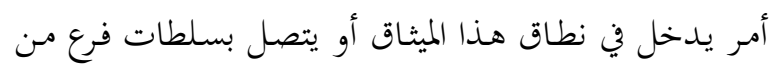

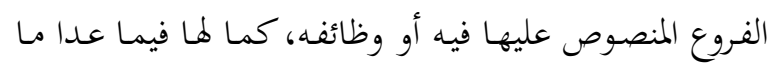

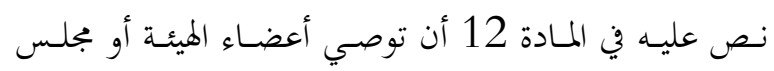
الأمن أو كليهما بما تراه في تلك المسائل والأمور ".

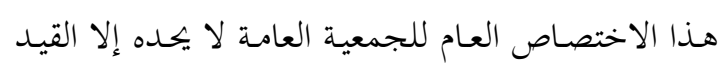

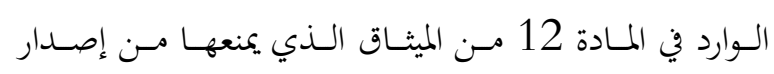

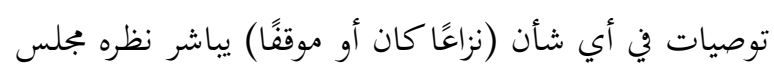
الأمن إلا إذا طلب منها هذا الأخير ذلك. لقـد كـان مـن نتيجـة الجهـود التي بــلت في أروقـة الأمـم

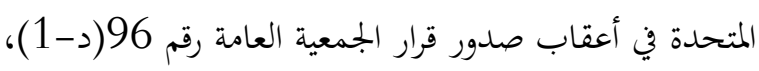

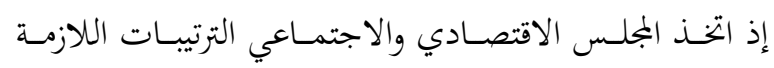

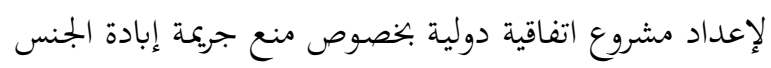

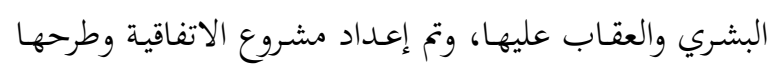

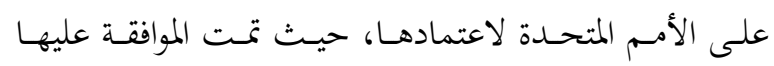

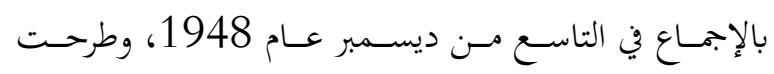
للتصديق عليها من جانب الدول، حيث دخلت حيز التنفيذ

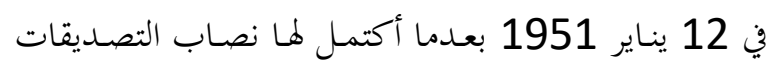
اللازم لنفاذها (32). وقــ أشـارت الاتفاقيـة إلى أن ارتكـاب الجريمـة لا يقتصـر

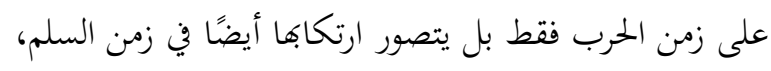

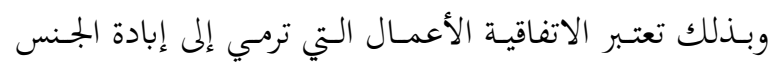

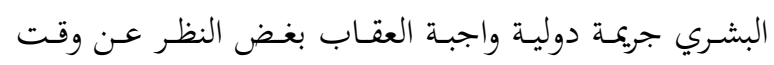

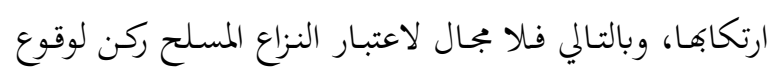
هذه الجريمة.

وقد عرفت المادة الثانية مـن الاتفاقية جريمة إبادة الجنس

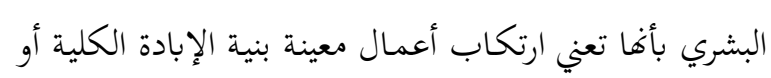
الجزئية لجماعة قومية أو إثنية أو عنصرية أو دينية (33). تم حددت تلك المادة بعض صور الأفعال التي يتحقق بها الركن المادي لجريمة الإبادة الجماعية، وذلك على سبيل المثال
الاختصاص بمحاكمة مرتكبي جريمة إبادة الجنس البشري، اما

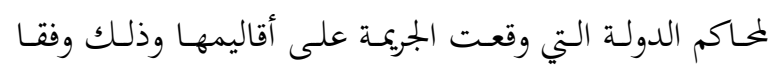

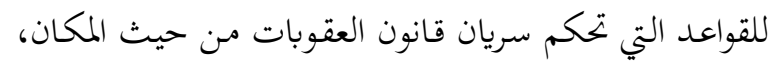

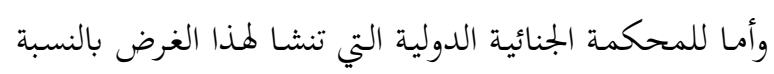

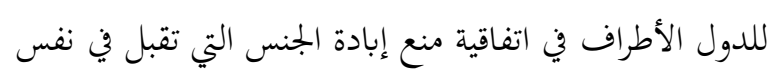

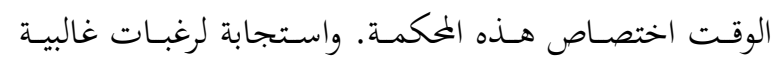

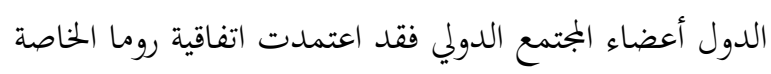

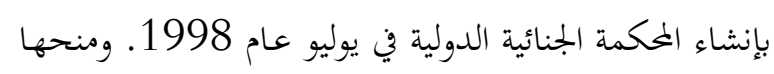
الاختصاص في محاكمة مرتكبي جرائم دولية أشد خطورة ومن بينها جريمة الإبادة الجماعية (31). وعليه ومما تقدم سنقسم دراسة هذا المبحث على مطلبين، بإنهاء وهما ما يأتي: وعليه ومان المطلب الأول: أهم جهود المنظمات والاتفاقيات الدولية لجريمة الإبادة الجماعية المطلب الثاني: المواجهة القضائية الدولية في مكافحة جريمة الإبادة الجماعية

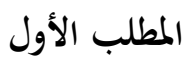

\section{جهود المنظمات والاتفاقيات الدولية لجريمة الإبادة الجماعية} أناط ميثاق الأمم المتحدة بمجلس الأمن والجمعية العامة العمل على الحفاظ على الأمن والسلم الدوليين، وإن جعل المانل

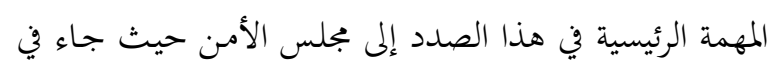

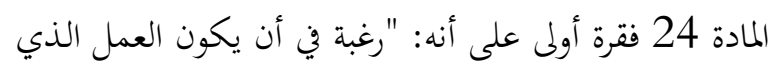

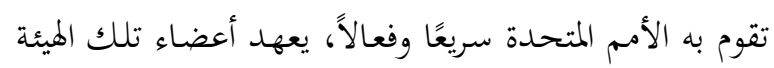
إلى مجلس الأمن بالتبعات الرئيسية في أمر حفظ الأمن والسلم

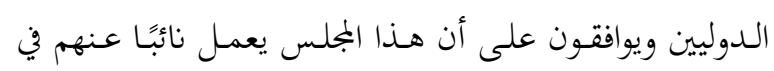

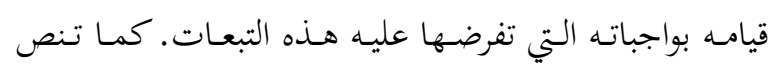

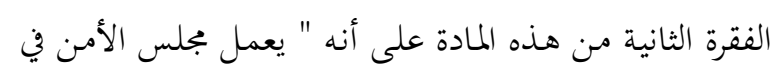

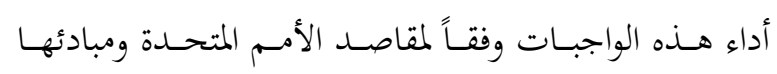
والسلطات الخاصة المخولة لمجلس الأمن لتمكينه مـ القيام

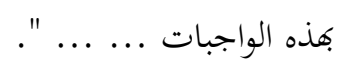

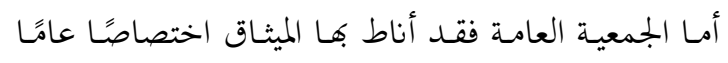

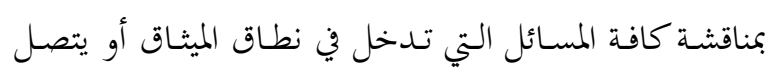


تلك الفئات ومنها فرنسا، إذ أضاف قانون العقوبات الفرنسي 1992 "أي جماعة تحدد على معايير عشوائية" (35).

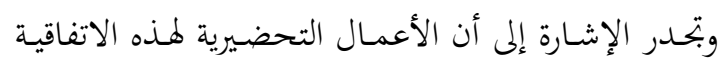

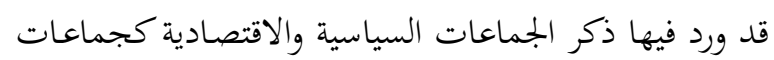
محمية بموجب هذه الاتفاقية، إلا أنه تم التغاضي عنها بحجة وتهة

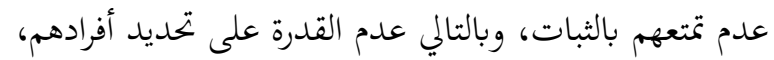

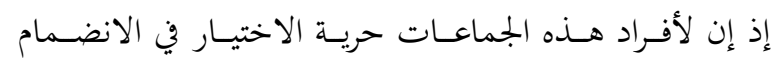

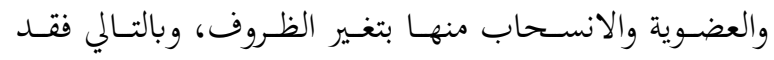

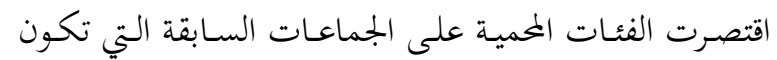
العضوية فيها للأفراد بصفة دائمة وتحدد بالولادة (36).

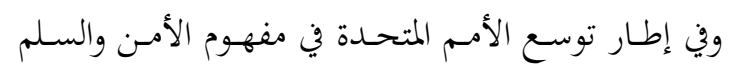

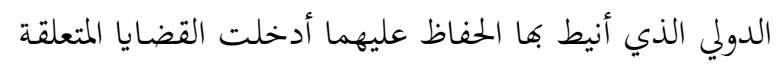

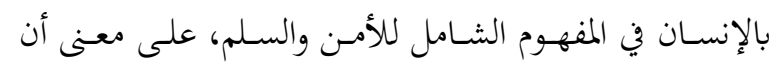
الأمم المتحدة قد جعلت أي إخلال جسيم يتهدد الجماعات البشرية بمثابة تمديد للأمن والسلم الدوليين (37).

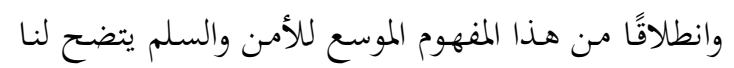
أن الأمم المتحدة لم تقتصر فحسب علي التهديد الذي يجري

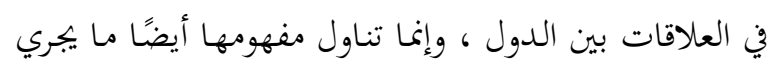

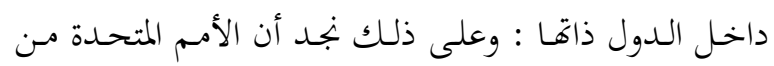

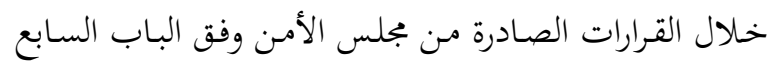

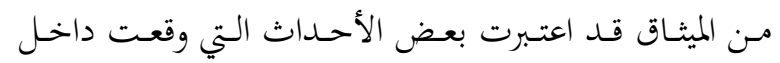

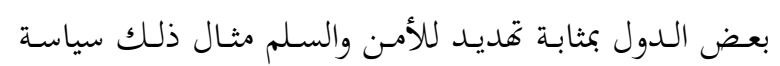

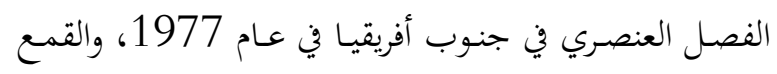

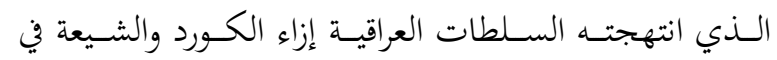
أعقـاب حـرب الخلـيج الأولى، والانتهـاك الجسـيم والممــهنج

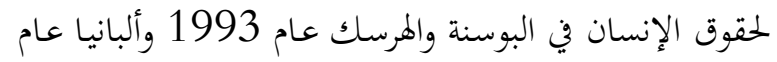
1997 وفي كوسـوفو عـام 1999، والإبادة الجماعيـة الـتي لئي حدثت في رواندا عام 1994.

لا الحصـر، كمـا نصـت الاتفاقيـة على خمس صـور للسـوك الإجرامي المؤتم لجريمة الإبادة الجماعية، وهي: 1. - ما إبادة الجنس البشري. 2. الاتفاق أو التآمر على ارتكاب جريمة إبادة الجنس. 3. التحريض المباشر والعلني على ارتكاب جريمة إبادة الجنس. 4. الشروع في ارتكاب جريمة إبادة الجنس. 5. الاشتراك في ارتكاب جريمة إبادة الجنس البشري.

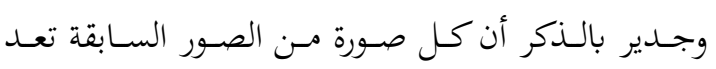
بمفردها جريمة مستقلة قائمة بذاتما وواجبة العقاب.

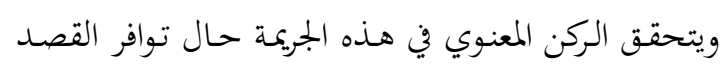

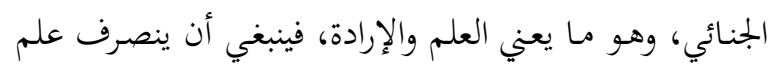

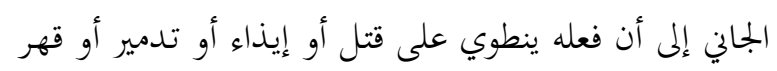

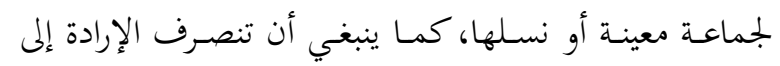
ذلك. إلا أن القصد الجنائي العام لا يكفي هنـا فقط لتحقيق

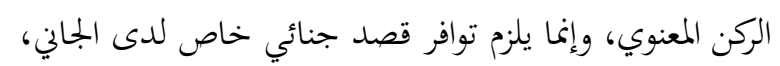

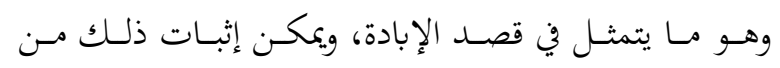

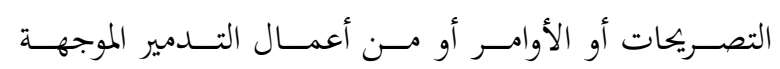
للجماعات (34) أمـا عـن الـركن الـدولي في تلـك الجريمـة فيشـترط أن يـتم

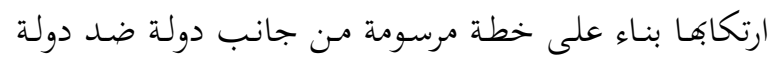

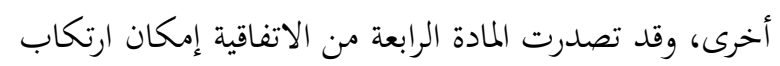

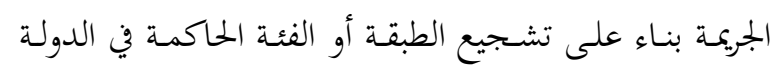
المرتكبة للجريمة.

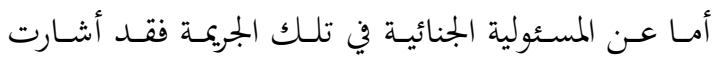

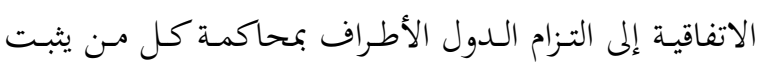

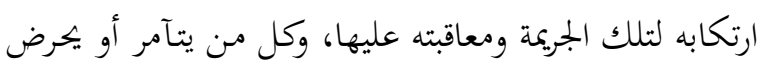

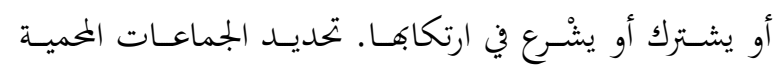

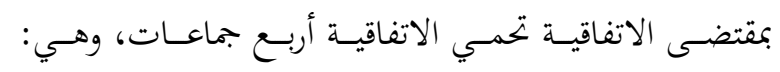

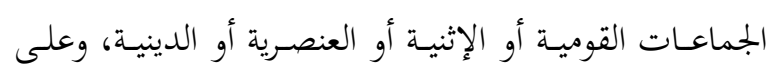

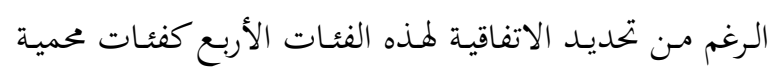

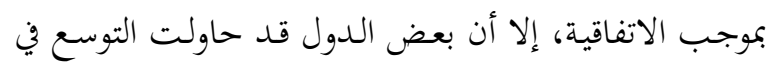


فه النظام الأساسي للمحكمة الجنائية الدولية بيوغوسلافيا

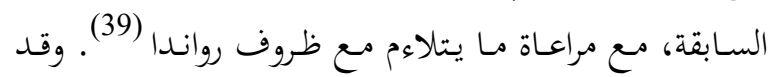

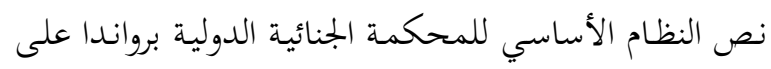

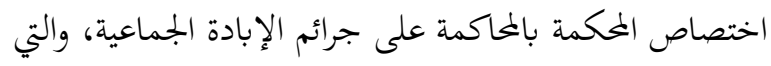

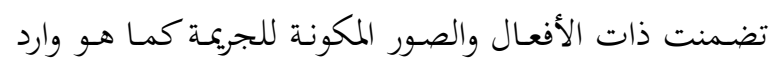
بالمكمة الجنائية الدولية بيوغوسلافيا السابقة. وقد فجت المحكمة الجنائية الدولية الدائمة برومـا عـام

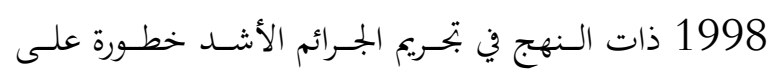

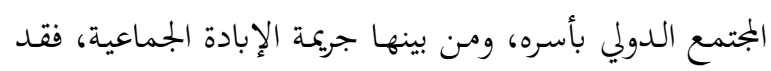

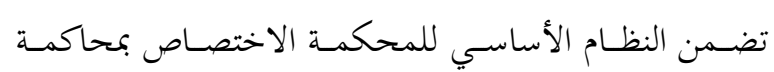

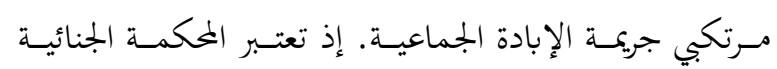

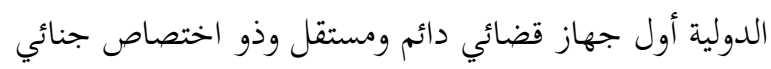

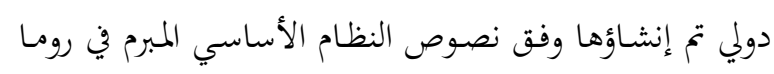

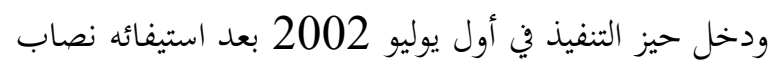
التصديقات اللازمة لنفاده. والوصف القانوين لهذه المحكمة أها منظمة دولية تتمتع بالشخصية القانونية الدولية (المادة 4 من

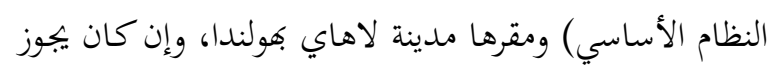

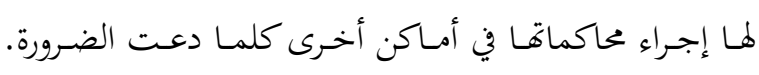
وتتبع المحكمة في أداء وظائفها القضائية المبادئ العامة المستقرة

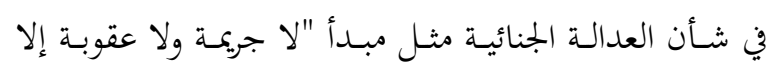

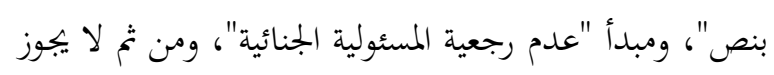

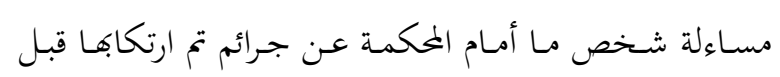

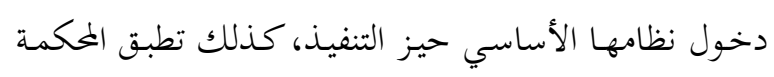

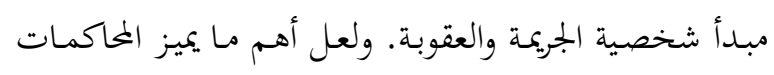

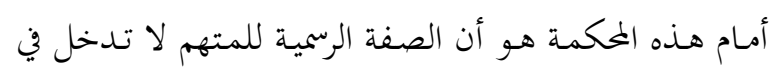

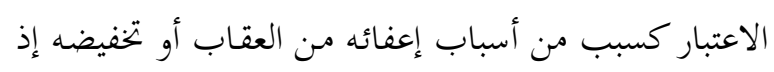

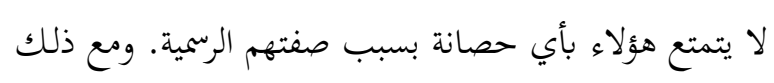

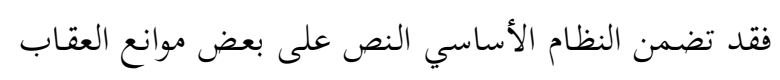

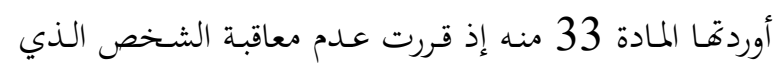

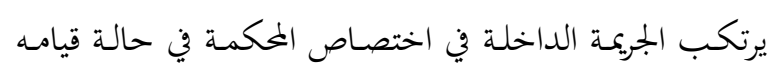

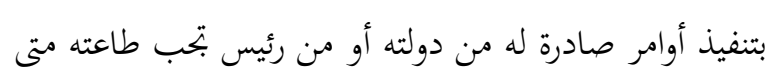

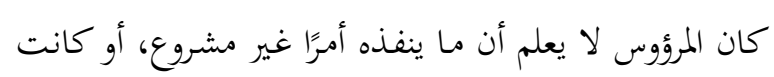

Nady-law2000@yahoo.com;

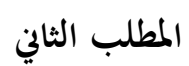

\section{المواجهة القضائية الدولية في مكافحة جريمة الإبادة}

الجماعية

إن الحياة الدولية قد شهدت مواجهة قضائية من خلال

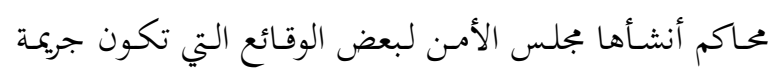

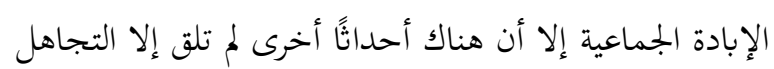

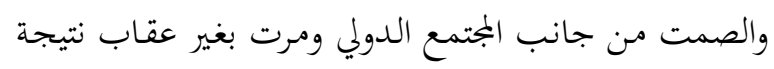

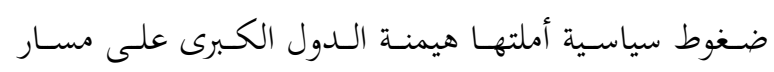

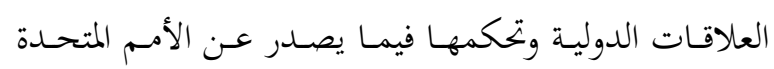

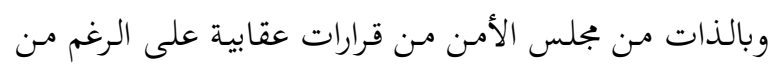

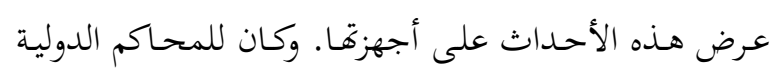

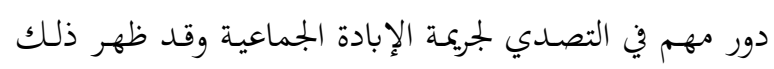
مـن خـلال محكمــة جـرائم الحــرب في يوغوســالافيا السـابقة

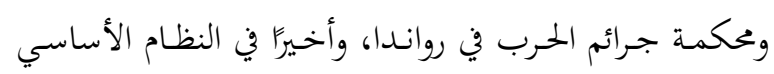

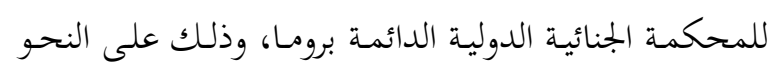
التالي: ففي يوغوسـلافيا السـابقة أصـدر مجلس الأمسن قراره رقم 808 لسنة 1993، وضمن فقرته الأولى قرار المجلس بإنشاء

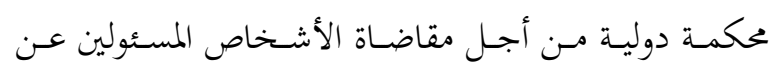

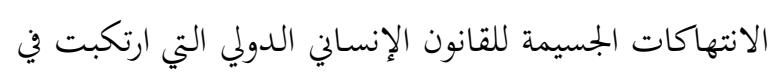
إقليم يوغوسلافيا السابقة منذ عام 1991 الإنسية لمانون الإناي الدولي التي

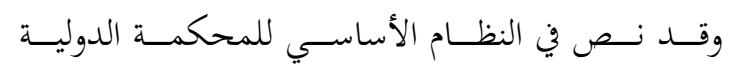

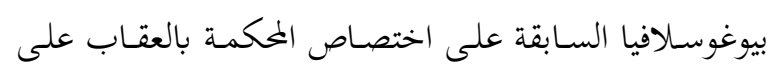

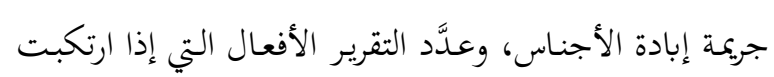

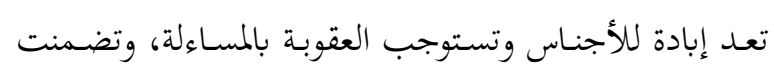

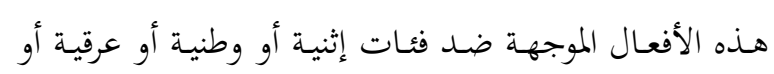

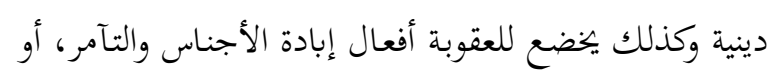

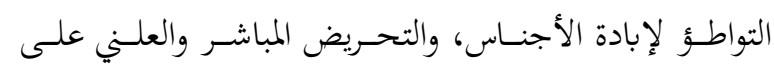

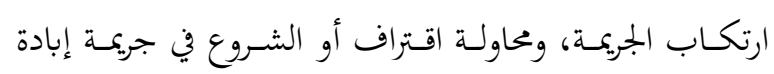
الأجناس، والاشتراك في جريمة إبادة الأجناس. أمـا في روانـدا فتـــ أصـدر مجلس الأمسن قراره رقـم 955

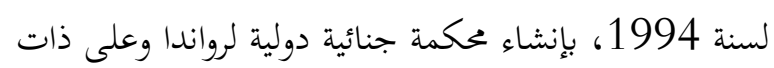


الجماعة، أو باتخاذ إجراءات تمنع تناسلها، أو النقل الإجباري لالأطفال من جماعة لجماعة أخرى.

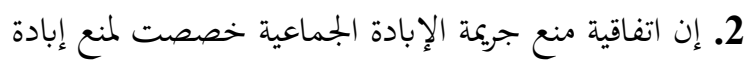

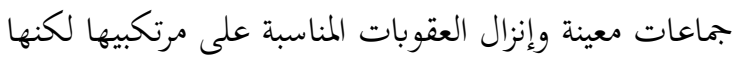
لم تشمل جميع صور الإبادة التي تتعرض لها هذه الجماعات؛

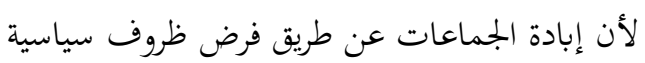
واقتصادية على جماعة معينة لا تدخل في حماية الاتفاقية. 3. ترتكب جريمة الإبادة الجماعية لأسباب قد تكون قومية،

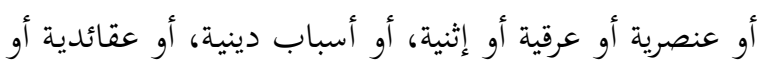

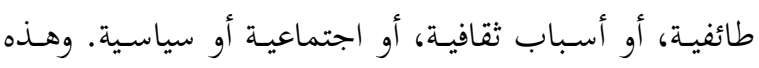

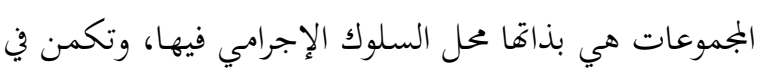

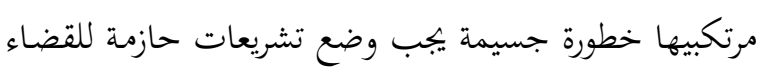
عليها.

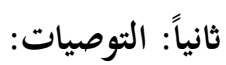
1. يجب على المجتمع الدولي الذي يعتبر الركن الأساسي في الذبات

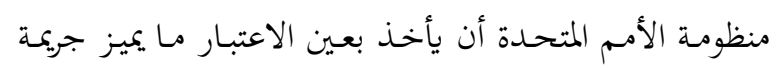

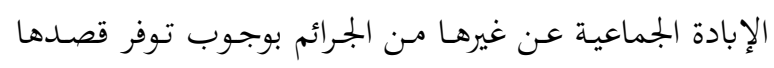

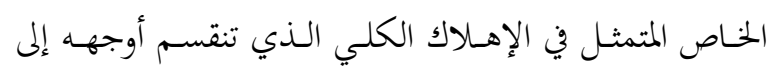

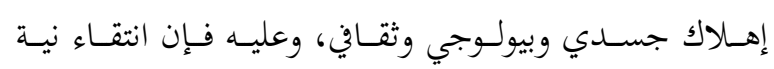

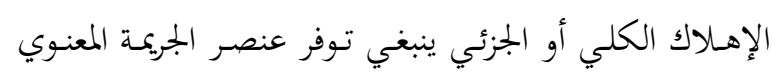

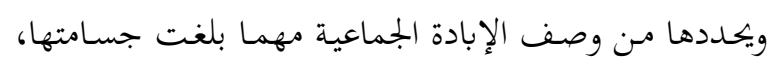

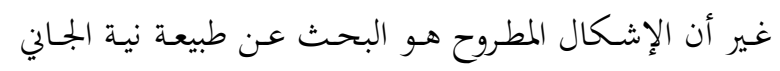

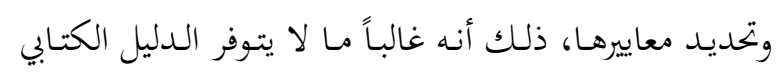
على نية الإهلاك لدى منفذو السياسات والأوامر العليا.

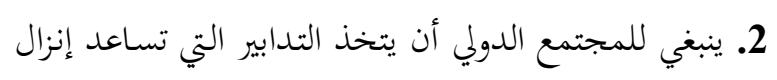

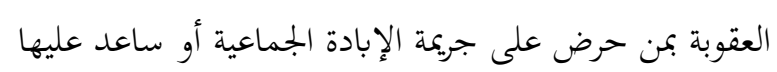

$$
\text { بشرط وجود هدف إجرامي مشترك. }
$$

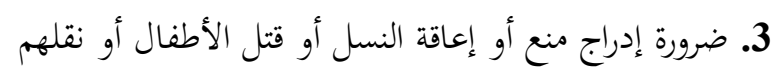
قسراً ضمن جرائم الإبادة الجماعية.

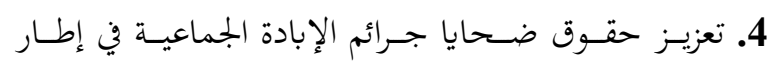

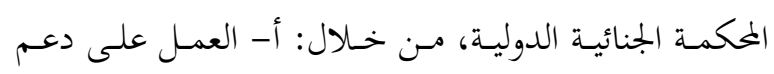

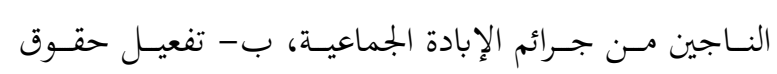

صفة عدم المشروعية غير واضحة، ومع ذلك فبإن الأعمال

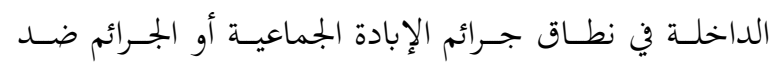

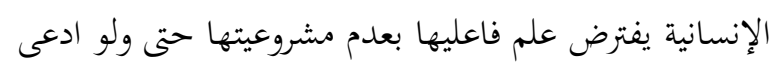

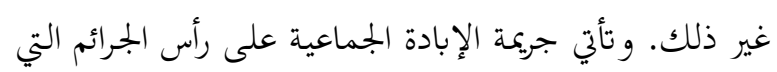

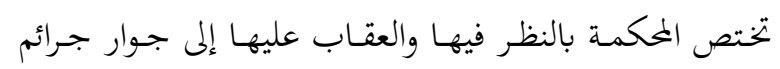
الحرب والجرائم ضد الإنسانية وجرائم العدوان (40).

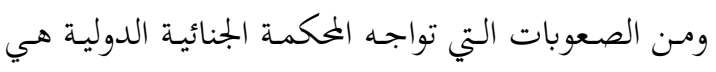

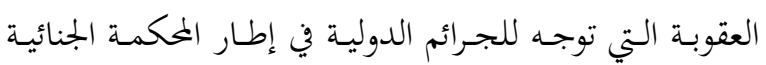

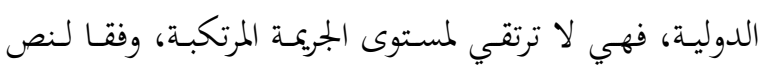
المادة (77) مـن النظام الأساسي للمحكمة الجنائية الدولية

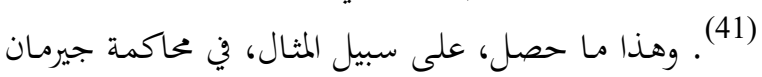

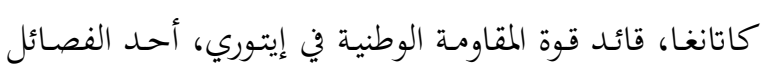

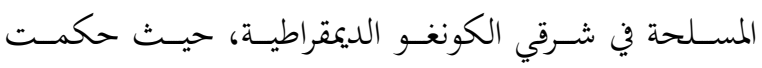

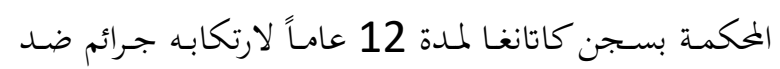

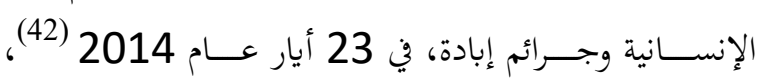

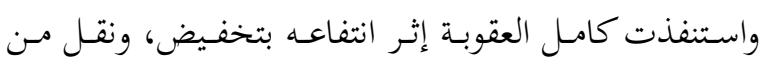

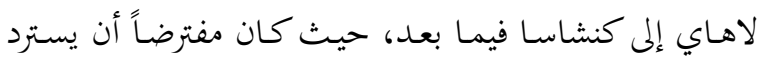
حريته، إلا أن كاتانغا وجد نفسه في حالة تتبع من قبل قضاء

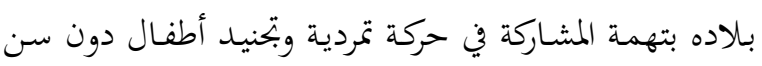
15 سنة، وجرائم ضد الإنسانية (43). الخاتمة

\section{من مجمل البحثث في موضسوعِ (دور التشـيع والقضساء}

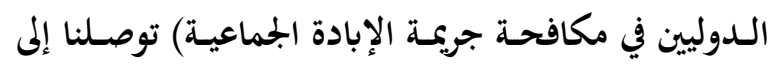

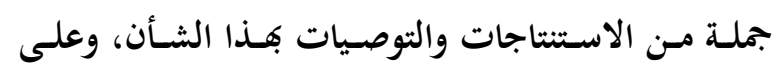

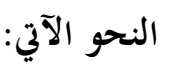
أولاً: الاستنتاجات: - (الاتي:

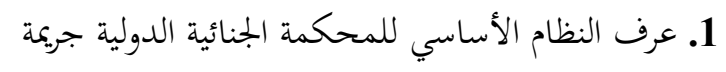

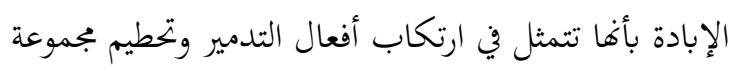
بسبب اشتراكها في اللغة أو الدين أو الجنس أو العادات

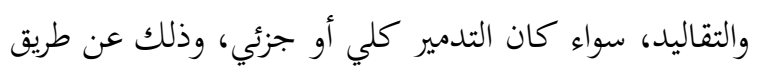
القتل، أو بأحداث أذى جسماني أو عقلي جسيم بأفراد 
(1) حسنين إبراهيم صالح عبيد: دراسة تحليلية تطبيقية في الجريمة

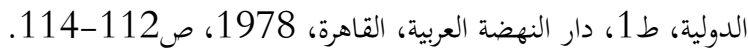

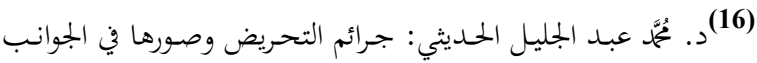

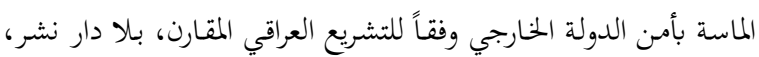

$$
\text { 1984، ص20 } 20 \text { وما بعدها. }
$$

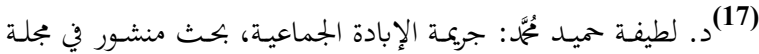

كلية الحقوق، بجلة علمية محكمة تصدرها كلية الحقوق، جامعة النهرين،

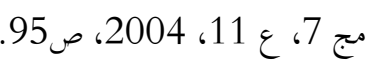

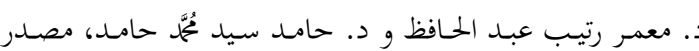

$$
\text { سابق، ص50 وما بعدها. }
$$

(19) وعلى أساس هذا "القصد الخاص" الواجب توافره لقيام جريمة الإبادة الجماعية وصفت الأخيرة باها "جريمة الجرائم"، فهو معيار أساسي يميزها

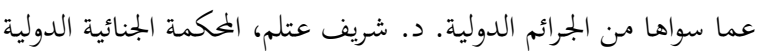
وتحدي الحصانة، بجلة اللجنة الدولية للصليب الأحمر، القاهرة، عدد 3-

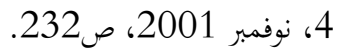
(20)د. شـريف عـتلم، المحكمــة الجنائيـة الدوليـة: المواءمـات الدسـتورية والتشريعية، الطبعة الخامسة، القاهرة، 2008، صب408

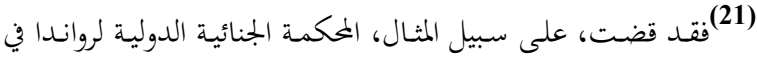
قضية "Akayesu" الى انه بالنظر للعدد الكبير مـن المذابح المرتكبة

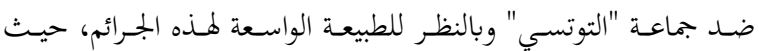
ارتكبــت في منـاطق عديـدة في روانـدا، ولأن الضـحايا جـرى اختيـارهم وتحديدهم بصورة عمدية ومنظمة وعلى أساس انتمائهم لجماعات أخرى تم إقصاؤها واستبعادها من حياة المجتمع ووجوده، فان المحكمة تستطيع الاستدلال على وجـود قصد خـاص لارتكاب جـرائم الإبادة الجماعية؛ ايمـن عبـد العزيز سـلامة، المسـئولية الدوليـة عـن ارتكـاب جريمـة الإبادة

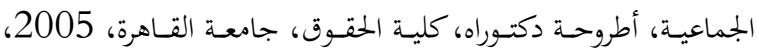
(22)للتفصيل في هذه الآراء الفقهية يراجع: بلول جمال، النظام القانوين

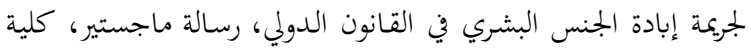

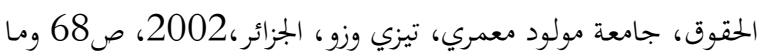

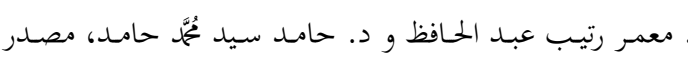

(24)فقد أقرت المحكمة الجنائية الدولية الخاصة بيوغوسلافيا السابقة بإمكانية تحقق جريمة الإبادة الجماعية حتى وإن ارتكبت في منطقة جغرافية ضيقة ما دام القصد الجنائي لمرتكبيها متجها نحو التدمير الكلي

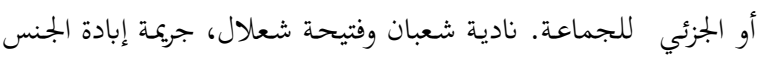

ضـحايا جــرائم الإبادة الجماعيـة في المشـاركة في الإجـــاءات القضائية أمام الملكمة الجنائية الدولية. 5. تفعيل دور صندوق الضحايا الاستئماني.

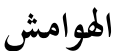

${ }^{(1)}$ Yves Ternon "Reflexions surlegenocide", in Gerard chaliand (Ed) "Lesminorites alagede Etat- nation", Paris: fagard, 1995, P 231.

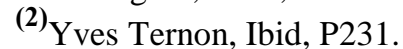

(3) د. معمر رتيب عبد الحافظ و د. حامد سيد مُعَّمَ حامد، تطور مفهوم

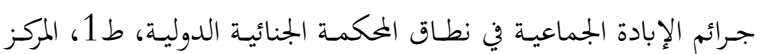
القومي للإصدارات القانونية، القاهرة، 2016، ص13.

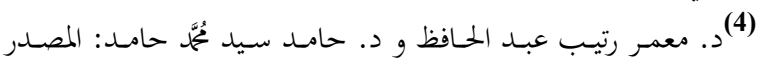

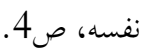
(5) (5لمادة (6) من النظام الأساسي للمحكمة الجنائية الدولية.

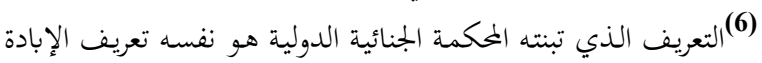
الجماعية وفقاً لاتفاقية عام 1948, الخاصة بمنع جريمة الإبادة الجماعية والمعاقبة عليها, وذكرت ذات الأفعال التي نصت عليها المادة الثانية من الاتفاقية باعتبارها تتثل الركن المادي لهذه الجريمة. إبراهيم سيد أحمد، نظرة

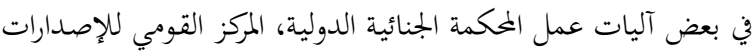
القانونية، القاهرة, 2011, ص بعض 131-132. (7) مُ مُحَّم عبد المنعم عبد الغنى، الجرائم الدولية :دارسة في القانون الدولي

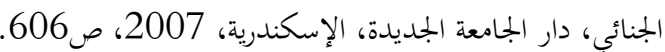

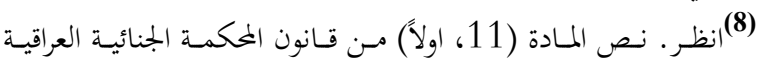

$$
\text { المختصة بالجرائم ضد الإنسانية رقم (1) لسنة } 2003 .
$$

(9)Convention on the Prevention and Punishment of the Crime of Genocide Adopted by Resolution 260 (III) A of the United Nations General Assembly on 9 December 1948. Article 2.

(10) Mark Levene, The European Rimlands 19391953: 2 (Crisis of Genocide) Volume II OUP Oxford (19 Dec 2013), p.10.

(11) Manus I. Midlarsky, The Killing Trap: Genocide in the Twentieth Century, Cambridge University Press (20 Oct 2005), p.6.

${ }^{(12)}$ Manus I. Midlarsky, Ibid, p.6.

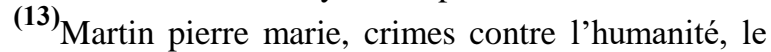
crime de génocide : Quelques paradoxes, Dalloz, n³1, paris, 2000, p 47.

(14)فــالا فريــد إبـراهيم: المسـؤولية المدنيـة الدوليـة عـن جريمــة الإبادة

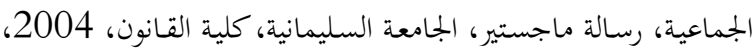
ص 40 
حيـدر غـازي فيصل الربيعي: المسؤولية الجنائيـة الدوليـة عن جريمـة

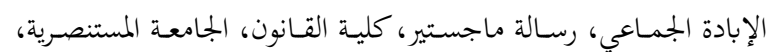
2006، ص212. (37) عادل ماجد: المحكمة الجنائية الدولية والسيادة الوطنية، مطبوعات مركز الدراسات السياسية والاستراتيجية، القاهرة، 2001، ص82

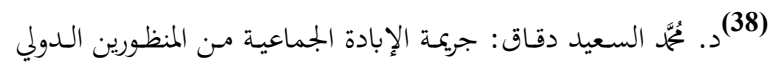
والإسلامي، بحث مقدم الى ندوة تطور العلوم الفقهية- مناهج التجديد الديني والفقهي، وزارة الأوقاف والشئون الدينية، سلطنة عمـان، 5-8 أبريل سنة 2015، ص 15.

${ }^{\text {(39) }}$ Project-International Criminal Court: Fact sheet 3: Prosecuting the crime of genocide-Al Index: IOR 40/04/00.

صلاح سعود الرقاد: جريمة الإبادة الجماعية أمـام المحكمة الجنائية

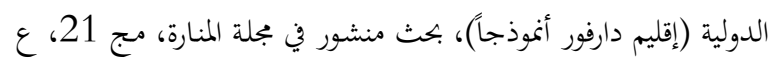
4، المغــرب، آب، 2015، ص363-364؛ د. تمُحَّ السـعيد دقــاق:

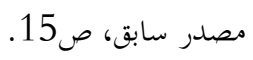

(41)نصـت المـادة (77) منـه على مــا يأتي: " 1-رهنـاً بأحكـام المـادة 110، يكون للمحكمة أن توقع على الشخص المدان بارتكاب جريمة في إطار المادة 5 من هذا النظام الأساسي إحدى العقوبات التالية- :أ-

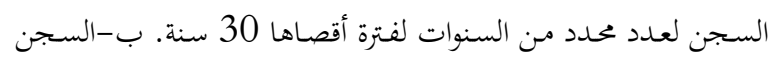

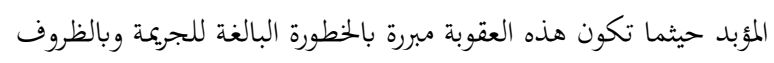

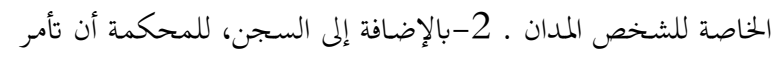

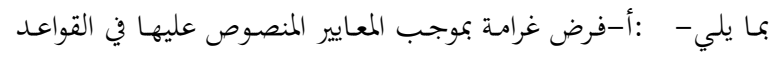
الإجرائية وقواعد الإثبات. ب-مصادرة العائدات والممتلكات والأصول

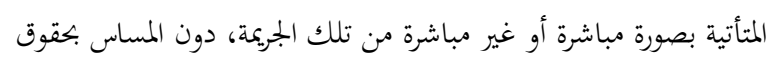

$$
\text { الأطراف الثالثة الحسنة النية". }
$$

(42) حيدر عبد الرزاق حميد: المخاوف الدولية من الانضمام للمحكمة المحة النحة

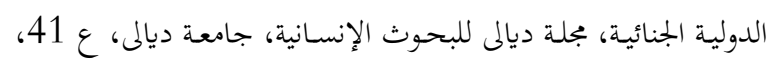
2009، ص 12 12-13. (13) (43) عدنان رحيم علي: دور القضاء الدولي في تطوير قواعد القانون

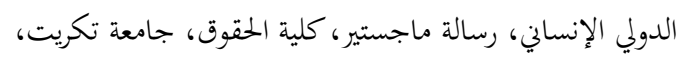

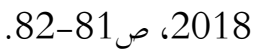

البشري في إطار المحكمة الجنائية الدولية، رسالة ماجستير، كلية الحقوق

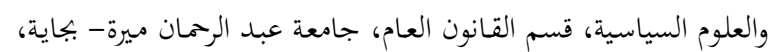

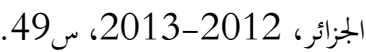

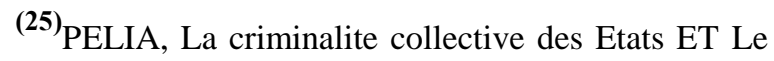
droit Penel de L'avenir, P.175.

GLASSER.Introduction a I etude due adroit international Penal, Beuxelles-Paris, 1954, P.11.

(26). حسنين إبراهيم صالح عبيد: مصدر سابق، ص234؛ د. محمود

عبد الفتاح يوسف: السياسة الدولية الجنائية لجريمة إبادة الجنس البشري-

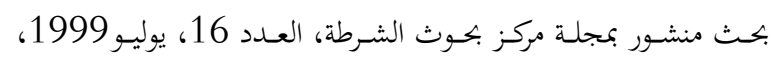

(27) ناظر احمـد منـديل: جريمة إبادة الجـنس البشري، رسـالة ماجستير،

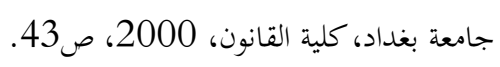

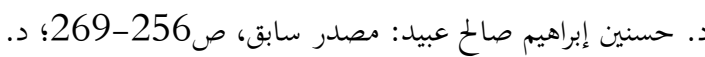

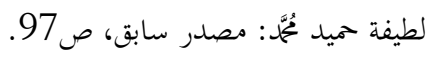
(29) جواد كاظم طراد الصريفي: الجرائم ضد الانسانية في ضوء أحكام

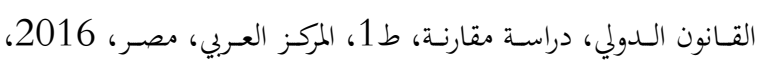
ص 125. (30)بيرو غالبريـث، هايـة العـراق، ط1، ترجمـة أياد أحمـ، البدار العربيـة للعلوم، ناشرون، بيروت، 2007، صائنة (31) انظر . المادة الخامسة من النظام الأساسي للمحكمة الجنائية الدولية

\section{- الوثيقة Aconf 183/9 صن}

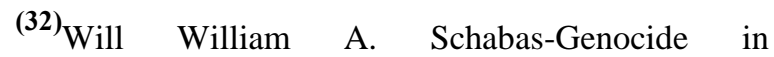
International Law- German edition; Hamburger Edition, Hamburg 2003.p:792.

$$
\text { (33) أيكن عبد العزيز سلامة: مصدر سابق، ص21-22) }
$$

(34) د. آدم سميان ذياب الغريري: الأوصاف الخاصة بجريمة الإبادة

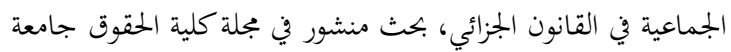

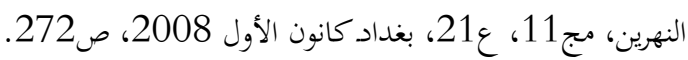

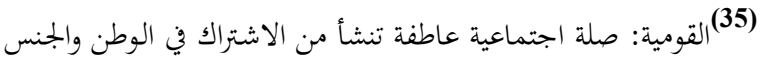
واللغـة والمنـافع، وقـد تنتهـي بالتضـامن والتعـاون الى الوحســة. إبـراهيم

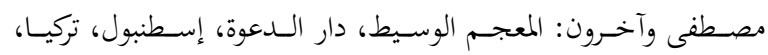

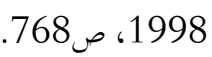

(Elementair, Qui concerne les Elements; reduit a l'essentiel, au minmum; les deux classes enter le corsrpr eparatoire et le cors moyen; dan les ecoles primaries: composant morceau, partie)

Hanna Kabbani and other- Le Dictionnaire Majeur Des Eleves- Dar Al- kotob Al-llmiyh, Beyrouth, 2006, p279. 
بلول جمال، النظام القانوني لجريمة إبادة الجنس البشري في القانون الدولي،

رسالة ماجستير، كلية الحقوق، جامعة مولود معمري، تيزي

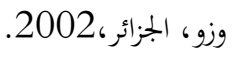

حيدر غازي فيصل الربيعي: المسؤولية الجنائية الدولية عن جريمة الإبادة الجماعي، رسالة ماجستير، كلية القانون، الجامعة المستنصرية،

.2006

عدنان رحيم علي: دور القضاء الدولي في تطوير قواعد القـانون الدولي

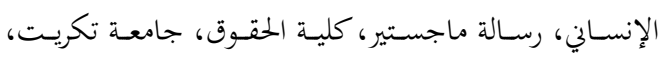

.2018

ثـالا فريد إبراهيم: المسؤولية المدنية الدولية عن جريمة الإبادة الجماعية،

رسالة ماجستير، الجامعة السليمانية، كلية القانون، 2004.

ناديـة شـعبان وفتيحـة شعلال، جريمـة إبادة الجــس البشـري في إطـار المحكمة الجنائية الدولية، رسالة ماجستير، كلية الحقوق والعلوم

السياسية، قسم القانون العام، جامعة عبد الرحمان ميرة- بجاية،

$$
\text { الجزائر، } 2012 .
$$

ناظر احمد منديل: جريمة إبادة الجنس البشري، رسالة ماجستير، جامعة

$$
\begin{aligned}
& \text { بغداد، كلية القانون، } 2000 . \\
& \text { ثالثاً: البحوث: }
\end{aligned}
$$

د. آدم سميان ذياب الغريري: الأوصاف الخاصة بجريمة الإبادة الجماعية في القانون الجزائي، بحثث منشور في بجلة كلية الحقوق جامعة

$$
\text { النهرين، مج11، ع21، بغداد كانون الأول } 2008 .
$$

حيـدر عبــ الـرزاق حميـد: المخــاوف الدوليـة مـن الانضـمام للمحكمــة الدولية الجنائية، مجلة ديالى للبحوث الإنسانية، جامعة ديالى،

$$
\text { . } 2009 \text { ع }
$$

د. شريف عتلم، المحكمة الجنائية الدولية وتحدي الحصانة، مجلة اللجنة الدولية للصليب الأحمر، القاهرة، عدد 3-4، نوفمبر 2001. صلاح سعود الرقاد: جريمة الإبادة الجماعية أمام المحكمة الجنائية الدولية (إقليم دارفور أنموذجاً)، بحث منشور في مجلة المنارة، مج 21،

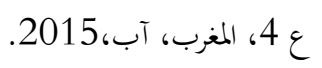

د. لطيفة حميد عُمَّم: جريمة الإبادة الجماعية، بحث منشور في مجلة كلية الحقـوق، مجلة علميـة محكمـة تصـدرها كليـة الحقـوق، جامعـة النهرين، مج 7، ع 11، 2004.

Nady-law2000@yahoo.com; Omarabbas93.aa@gmail.com
إبراهيم سيد أحمد، نظرة في بعض آليات عمل المحكمة الجنائية الدولية، المركز القومي للإصدارات القانونية، القاهرة, 2011. إبراهيم مصطفى وآخرون: المعجم الوسيط، دار الدعوة، إسطنبول، تركيا، .1998 بيرو غالبريث، فاية العراق، ط1، ترجمة أياد أحمد، الدار العربية للعلوم،

$$
\text { ناشرون، بيروت، } 2007 .
$$

جواد كاظم طراد الصريفي: الجرائم ضد الانسانية في ضوء أحكام القانون الدولي، دراسة مقارنة، ط1، المركز العربي، مصر، 2016. د. حسنين إبراهيم صالح عبيد: دراسة تحليلية تطبيقية في الجريمة الدولية، ط1، دار النهضة العربية، القاهرة، 1978. د. شـريف عـتلم، المحكمــة الجنائيسة الدوليـة: المواءمـات الدسـتورية والتشريعية، الطبعة الخامسة، القاهرة، 2008. عادل ماجد: المحكمة الجنائية الدولية والسيادة الوطنية، مطبوعات مركز الدراسات السياسية والاستراتيجية، القاهرة، 2001. د. عُمَّمَ عبد الجليل الحديثي: جرائم التحريض وصورها في الجوانب الماسة بأمـن الدولـة الخـارجي وفقـاً للتشـيع العراقي المقـارن، بـلا دار نشر، د. مُحَّم عبد المنعم عبد الغنى، الجرائم الدولية :دارسة في القانون الدولي الجنائي، دار الجامعة الجديدة، الإسكندرية، 2007. د. معمر رتيب عبد الحافظ و د. حامد سيد تُحََّ حامد، تطور مفهوم جرائم الإبادة الجماعية في نطاق المحكمة الجنائية الدولية، ط1، المركز القومي للإصدارات القانونية، القاهرة، 2016.

ثانياً: الرسائل والأطاريح الجامعية: ايمـن عبـد العزيز سـلامة، المسئولية الدوليـة عـن ارتكـاب جريمـة الإبادة الجماعيـة، اطروحسة دكتـوراه، كليـة الحقـوق، جامعـة القـاهرة، 
Hanna Kabbani and other- Le Dictionnaire Majeur Des Eleves- Dar Al- kotob Al-llmiyh, Beyrouth, 2006.

PELIA, La criminalite collective des Etats ET Le droit Penel de L'avenir.

Project-International Criminal Court: Fact sheet 3: Prosecuting the crime of genocide-Al Index: IOR 40/04/00.

Mark Levene, The European Rimlands 1939-1953: 2 (Crisis of Genocide) Volume II OUP Oxford (19 Dec 2013).

Martin pierre marie, crimes contre l'humanité, le crime de génocide : Quelques paradoxes, Dalloz, n³1, paris, 2000.

Manus I. Midlarsky, the Killing Trap: Genocide in the Twentieth Century, Cambridge University Press (20 Oct 2005).

Will William A. Schabas-Genocide in International Law- German edition; Hamburger Edition, Hamburg 2003.

Yves Ternon "Reflexions surlegenocide", in Gerard chaliand (Ed) "Lesminorites alagede Etatnation", Paris: fagard, 1995.

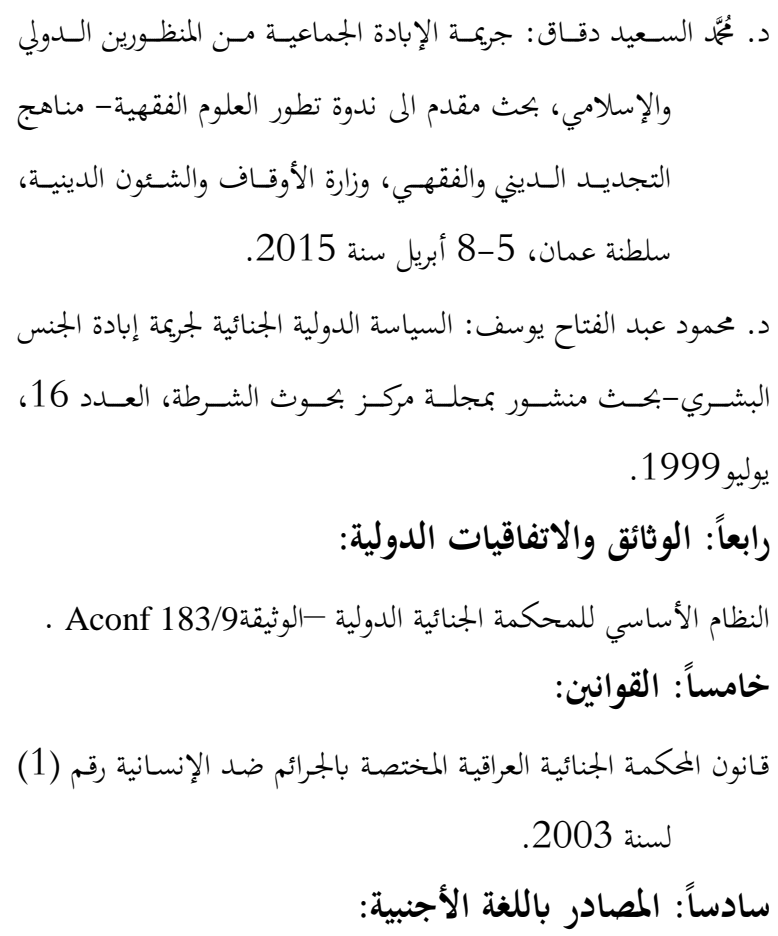

Convention on the Prevention and Punishment of the Crime of Genocide Adopted by Resolution 260 (III) A of the United Nations General Assembly on 9 December 1948.

GLASSER.Introduction a I etude due adroit international Penal, Beuxelles-Paris, 1954. 


\title{
THE ROLE OF INTERNATIONAL LEGISLATION AND JUSTICE IN COMBATING GENOCIDE
}

\author{
NAef AHMed Dahi Al Shamari and Omar Abbas KhUder Al AaAbDi \\ Dept. Law, College of law, university of Takert-Iraq
}

\begin{abstract}
This research is one of the studies that show the gravity of international crimes against humanity, and international efforts to ensure human rights work, justice for people, and to stop inhuman practices against civilians during wars.

The study aims to review the most important international efforts to define the crime of genocide, criminalize and punish it, as this crime remains non-criminal and unpunished in the national laws of states, as well as knowing effective ways to tackle and punish this crime internationally, and prevent its occurrence by states in the future.

International crimes affecting humankind are among the most serious crimes against people, as they involve a violation of the life of a person or a group of people, or their liberty, rights, or human beings, and these crimes together constitute what are called human crimes. And since the concept of international crime was taking shape through the trials that took place in Nuremberg for the Nazi leaders and in Tokyo for the Japanese leaders, they were charged with crimes against humanity and the term "genocide" was first described as a description of facts and not a legal term, but the association The General Assembly of the United Nations adopted on December 11, 1946 a recommendation in which it described genocide as a crime of international law.
\end{abstract}

KEY WORDS: humankind, against humanity, mass murder, murder. 